University of Rhode Island

DigitalCommons@URI

Open Access Master's Theses

2013

\title{
A Strain-Based Procedure to Screen for Wave-Induced Pore Pressure Generation in the Seabed
}

Anthony James Julian

University of Rhode Island, ajjulian17@gmail.com

Follow this and additional works at: https://digitalcommons.uri.edu/theses

\section{Recommended Citation}

Julian, Anthony James, "A Strain-Based Procedure to Screen for Wave-Induced Pore Pressure Generation in the Seabed" (2013). Open Access Master's Theses. Paper 82.

https://digitalcommons.uri.edu/theses/82

This Thesis is brought to you for free and open access by DigitalCommons@URI. It has been accepted for inclusion in Open Access Master's Theses by an authorized administrator of DigitalCommons@URI. For more information, please contact digitalcommons-group@uri.edu. 


\section{A STRAIN-BASED PROCEDURE TO SCREEN FOR WAVE-INDUCED PORE PRESSURE GENERATION IN \\ THE SEABED}

BY

ANTHONY JULIAN

A THESIS SUBMITTED IN PARTIAL FULFILLMENT OF THE REQUIREMENTS FOR THE DEGREE OF MASTER OF SCIENCE IN OCEAN ENGINEERING 
MASTER OF SCIENCE THESIS

OF

ANTHONY JULIAN

APPROVED:

Thesis Committee:

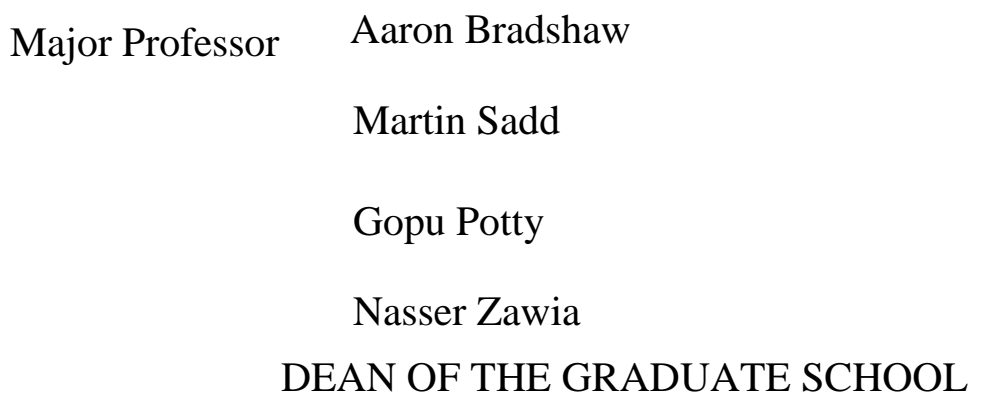

UNIVERSITY OF RHODE ISLAND

2013 


\begin{abstract}
This manuscript presents a strain-based procedure to screen for wave-induced residual pore pressures in the seabed. The generation of residual pore pressures can lead to instabilities and/or liquefaction within the seabed producing undesired consequences in the marine environment. Currently, techniques to predict waveinduced liquefaction are governed from seismic-based principles; however, differences between these two contrasting mechanisms (earthquakes and ocean waves) creates uncertainties within the soil relating to: the determination of an equivalent number of loading cycles representing the irregular time history of ocean wave loading, the prediction of cyclic resistance at low levels of effective stress (i.e. in near-surface sediments), and pore pressure generation in silty/clayey soils. First, the strain-based model is described. Linear elastic finite element analyses are used to develop normalized charts for estimating the cyclic shear stresses in an inhomogeneous seabed. The model is validated from existing wave tank experiments on silt. This comparison showed the generation and non-generation of excess pore pressure corresponded to factors of safety less than and greater than one respectively. Lastly, a case study is presented to illustrate the practical implementation of the model.
\end{abstract}




\section{ACKNOWLEDGMENTS}

It is with immense gratitude that I acknowledge the support from my major professor Aaron Bradshaw. My entire experience with Professor Bradshaw has been excellent and can be attributed to all of his advice and kindness throughout this

process. I am indebted to Professor Bradshaw for giving me this opportunity, and I wish nothing but the best for him and his family.

I would like to give a special thanks to the Rhode Island Water Resources Center who has funded my research studies. Being financially secured provided me with a comfortable research atmosphere to conduct this project.

I would also like to thank my friends at URI. Their friendships have made my experience at URI unforgettable. Our times in school, playing intramurals, surfing, and hanging out brought a balanced lifestyle of hard work and fun.

I would like to specifically thank Jen Giard and Professor Potty for allowing me to join on their field test. This experience (although freezing cold) was enjoyable and I benefitted from the integration of their research into my work.

Lastly, I would like to thank my family. Without their support and influence my accomplishments to recent would not be possible. To my brother and sisters, Andrew, Monica and Sabrina for their continued love while enduring (at times) a protective and stubborn older brother. To my father Albert, who has embodied what it means to work hard in this life and has selflessly provided the opportunity for us children to have the opportunity to succeed. To my mother Patricia, the most unselfish person I have known. Her passion for math and science as has greatly 
influenced my life and for me to follow in her footsteps as an engineer is amazing. To my Grandparents Albert and Gilda, for blessing me with the most treasured times of my life spent during the summers at their house on Cape Cod, and to my Grandparents Dominic and Patricia, who I am very grateful to still have in my life.

Due to my family's large Italian heritage, the amount of space needed to thank everyone is impractical. For this, I would like to say to everybody -- I thank you for all your love and support. 


\section{PREFACE}

This thesis is written in manuscript format with the intent of future publication in a scholarly journal. The manuscript is co-authored with Aaron Bradshaw and discusses a strain-based procedure to screen for wave-induced pore pressure generation in the seabed. 


\section{TABLE OF CONTENTS}

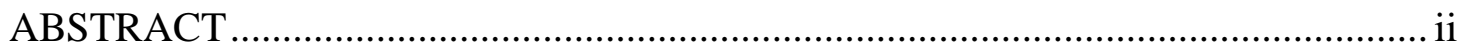

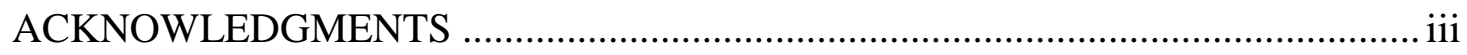

PREFACE …

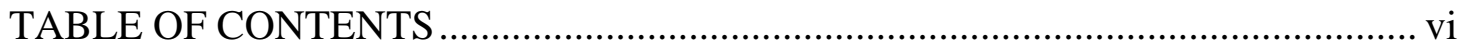

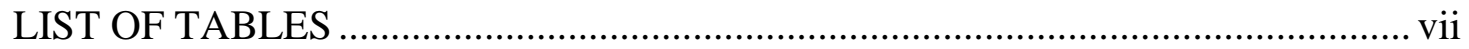

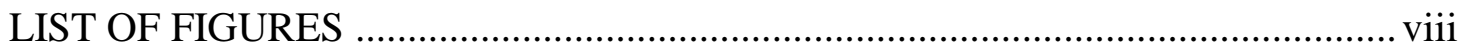

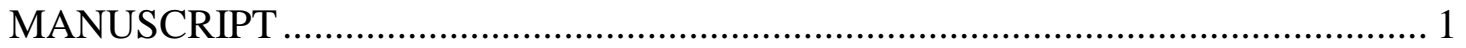

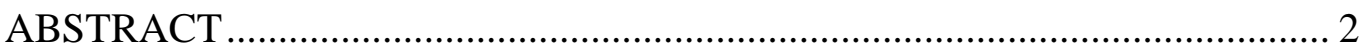

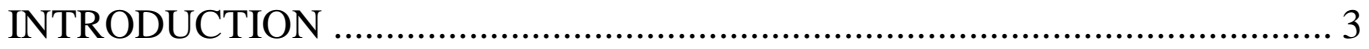

DESCRIPTION OF STRAIN-BASED MODEL............................................... 7

SHEAR STRESS INFLUENCE FACTORS FOR INHOMOGENEOUS

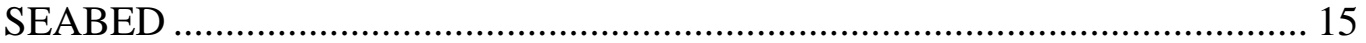

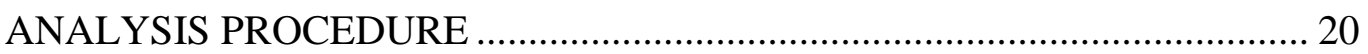

VALIDATION OF THE STRAIN-BASED PROCEDURE ............................... 22

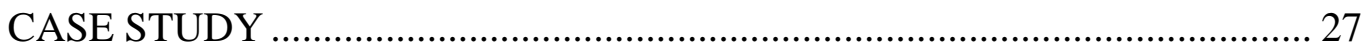

SUMMARY \& CONCLUSION ................................................................... 30

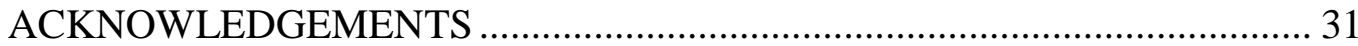

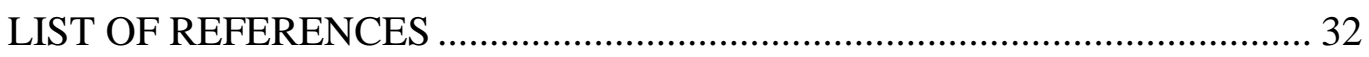

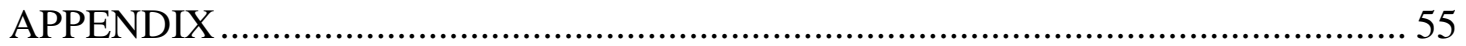

A. MATLAB CODE FOR CASE STUDY ………………………………........ 55 


\section{LIST OF TABLES}

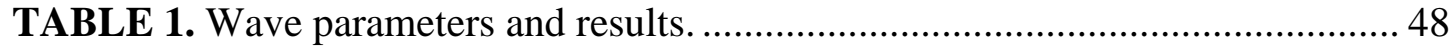




\section{LIST OF FIGURES}

FIG. 1. Schematic of harmonic water-wave loaded seabed.

34

FIG. 2. Pore pressure ratios generated in a variety of sands under cyclic loading

(Vucetic, 1994 after Dobry et al. 1982).

FIG. 3. Effect of plasticity index on threshold shear strain for cyclic pore-water

pressure (Hsu \& Vucetic, 2006)

FIG. 4. Non-dimensional shear stress profile of analytical solution derived by

Fung,1965.

FIG. 5. Numerical models of two-layer and linear increasing shear modulus profiles.

FIG. 6. Shear stress profile of a two layered seabed for different stiffness ratios, Top layer thickness $=\lambda / 16$ 39

FIG. 7. Shear stress profile of a two layered seabed for different stiffness ratios, Top layer thickness $=\lambda / 8$. 40

FIG. 8. Shear stress profile of a two layered seabed for different stiffness ratios, Top layer thickness $=\lambda / 4$. 41

FIG. 9. Shear stress profile of a two layered seabed for different stiffness ratios, Top layer thickness $=\lambda / 2$. 42

FIG. 10. Shear stress profile of a two layered seabed for different stiffness ratios, Top layer thickness $=3 \lambda / 4$

FIG. 11. Non-dimensional shear stress profile of linear increasing shear modulus... 44 
FIG. 12. Wave tank facility (Clukey, et al. 1985).

FIG. 13. Finite element model of wave tank facility. 46

FIG. 14. Shear modulus measured from simple shear tests for Danby Silt and Filter

Sand under low confining stresses (data obtained by Clukey et al. 1983).

FIG. 15. Shear stress profile for wave tank test 7-1, 7-2, \& 7-3....................... 49

FIG. 16. Modeled factor of safety and pore pressure ratio (Clukey, Test 7-1)........ 50

FIG. 17. Modeled factor of safety and pore pressure ratio (Clukey, Test 7-2)......... 51

FIG. 18. Modeled factor of safety and pore pressure ratio (Clukey, Test 7-3)......... 52

FIG. 19. Small strain shear modulus profiles for the cap and silt layers.................. 53

FIG. 20. Factor of safety against excess pore pressure for the short term and long

term. 
MANUSCRIPT

A STRAIN-BASED PROCEDURE TO SCREEN FOR PORE PRESSURE GENERATION IN THE SEABED

TO BE SUBMITTED TO

THE JOURNAL OF GEOTECHNICAL AND GEOENVIRONMENTAL

ENGINEERING 


\section{ABSTRACT}

This manuscript presents a strain-based procedure to screen for wave-induced residual pore pressures in the seabed. The generation of residual pore pressures can lead to instabilities and/or liquefaction within the seabed producing undesired consequences in the marine environment. Currently, techniques to predict waveinduced liquefaction are governed from seismic-based principles; however, differences between these two contrasting mechanisms (earthquakes and ocean waves) creates uncertainties within the soil relating to: the determination of an equivalent number of loading cycles representing the irregular time history of ocean wave loading, the prediction of cyclic resistance at low levels of effective stress (i.e. in near-surface sediments), and pore pressure generation in silty/clayey soils. First, the strain-based model is described. Linear elastic finite element analyses are used to develop normalized charts for estimating the cyclic shear stresses in an inhomogeneous seabed. The model is validated from existing wave tank experiments on silt. This comparison showed the generation and non-generation of excess pore pressure corresponded to factors of safety less than and greater than one respectively. Lastly, a case study is presented to illustrate the practical implementation of the procedure. 


\section{INTRODUCTION}

Soil strength is governed by effective stress which is defined as the difference between the total vertical overburden stress $\left(\sigma_{v}\right)$ and the pore pressure $(u)$ for any location within the soil. If the overburden stress remains constant, an increase in pore pressure will result in a decrease in the soil's effective stress thus reducing soil strength. The phenomenon known as liquefaction occurs when pore pressure increases to the point where the effective stresses between the individual grains in the soil vanish, and therefore the water-sediment mixture as a whole acts likes a fluid. Literature has cited several cases in the marine environment where liquefaction resulted in the failures of buried pipelines, large breakwater structures, and sea mines (Sumer and Fredsee, 2002).

There are two types of ocean wave-induced liquefaction: transient (or momentary) liquefaction and residual liquefaction. Momentary liquefaction refers to the repeated and instantaneous loss of effective stress due to the upward vertical pressure gradient in the soil during the passage of wave troughs (Sumer and Fredsee 2002). Residual liquefaction refers to the accumulation of excess pore pressures associated with plastic deformation under cyclic loading. In non-plastic sands and silts the effective stress may be reduced to zero, a condition referred to as initial liquefaction. In plastic silts and clays the effective stress does not typically reach zero because of cohesion, commonly referred to as "cyclic softening". This paper focuses on the accumulation of excess pore water pressures from ocean wave loading.

Seed and Rahman (1978) were the first to develop a method to predict ocean wave-induced liquefaction in the seabed. Their method encompasses both generation 
and dissipation mechanisms of pore pressure for clean sands. Pore pressure generation is based on laboratory derived equations that relate the pore pressure ratio, $\mathrm{r}_{\mathrm{u}}$, defined as the excess pore pressure divided by the initial effective vertical stress, to the cycle ratio, $\mathrm{N} / \mathrm{N}_{1}$, where $\mathrm{N}$ is the number of stress cycles during a storm and $\mathrm{N}_{1}$ is the number of cycles to cause liquefaction. Their method uses equations that are solved using a numerical analysis allowing the seabed to be discretized into layers representing different soil characteristics and rates of pore pressure generation.

Finn et al. (1983) developed a computer program called STAB-W to compute residual pore pressures in the seabed and evaluate liquefaction potential. Their analysis is a generalization of Seed and Rahman's approach; however, it considers the changes to moduli and shear stress levels as excess pore pressure accumulates.

Although the above procedures may be appropriate for projects in which liquefaction could result in costly and unfavorable consequences, simplified approaches have been proposed for evaluating sands to reduce time and expense by conservatively assuming undrained conditions (e.g. Nataraja and Gill 1983; Ishihara and Yamazaki 1984). Nataraja and Gill's method is based on correlations developed for seismic liquefaction that relate cyclic strength to Standard Penetration Test (SPT) blow counts. The correlations were adjusted for ocean wave loading to account for more severe degradation effects and higher numbers of cycles. An analysis is performed by estimating the cyclic strength from SPT blow counts and comparing them to the cyclic shear stresses induced in the seabed for an equivalent number of ocean wave cycles. 
Ishihara and Yamazaki (1984) accounted for the difference in stress path between ocean wave and earthquake loading by performing undrained cyclic triaxial torsion shear tests on loose sands. This experimental data is used in part to derive charts that require deep water ocean wave design parameters. These charts assume a seabed that is a homogenous elastic half-space and are used to find the near-shore location where the cyclic stress ratio at the mud line is equal to the cyclic stress ratio at failure.

Other methods have been used to assess pore pressure generation at specific sites consisting of silts and clays (Lee and Focht, 1975; Clukey et al. 1983). These methods have included the use of extensive laboratory cyclic testing (e.g. Lee and Focht, 1975) or wave tank experiments (e.g. Clukey et al., 1983).

The seabed in the marine environment is diverse and therefore procedures to predict the generation of pore pressure in the seabed must be able to encompass a wide range of conditions. Currently, procedures are based on experiments conducted on clean sands; however, the seabed is composed of stratified deposits often containing both plastic and non-plastic fines. These conditions make it difficult to estimate the relative density of the seabed to determine an appropriate cyclic resistance ratio for these stress-based methods. Moreover, obtaining undisturbed samples for laboratory tests in the soft or loose near-surface sediments is difficult or nearly impossible. Stress-based methods also require the determination of an equivalent number of loading cycles to cause liquefaction; however there are no well-established procedures for storm-wave loading for liquefaction evaluations. 
To avoid some of the limitations and uncertainties with the simplified methods described above this paper presents a simple strain-based approach to screen for waveinduced pore pressure generation. This approach may be an improvement over current stress-based approaches given that shear strains are more closely related to pore pressure generation than shear stresses (Seed et al. 1985). A detailed description of the method, a comparison of the method to wave tank experiments, and a case study illustrating the feasibility of the method are presented below. 


\section{DESCRIPTION OF STRAIN-BASED MODEL}

A simple strain-based model to screen for wave-induced pore pressure generation in the seabed is derived after Bradshaw (2012). Figure 1 illustrates the process of a seabed subjected to harmonic water-wave loading. It can be seen that the differential loading due to the harmonic water-wave produces shear and normal stresses within the seabed. The magnitude of these induced cyclic stresses will depend on the wave height $(\mathrm{H})$, still water depth $(\mathrm{d})$, wavelength $(\lambda)$, and depth below the surface of the seabed $(\mathrm{z})$. The procedure presented herein uses a total stress analysis whereby the shear strains induced within the seabed are compared to the shear strain required to generate excess pore pressure (i.e. "threshold shear strain").

The threshold shear strain concept was initially conceived by Dobry et al. (1982) for seismic soil liquefaction potential. In their study, multiple undrained cyclic triaxial tests were conducted using 8 different sands, 4 sample preparation techniques, and a wide range of confining stresses. These results are shown in Figure 2 which plots the pore pressure ratio, defined as the excess pore pressure divided by the initial effective confining pressure, vs. the cyclic shear strain amplitude. Figure 2 shows that the threshold shear strain is independent of soil type, confining stress, and sample preparation method. It can also be seen from Figure 2 that cyclic strains below the threshold shear strain do not generate excess pore pressure and therefore the potential to generate excess pore pressure be expressed as a factor of safety (FS),

$$
F S=\frac{\gamma_{t}}{\gamma}
$$


where $\gamma_{t}=$ the threshold shear strain and $\gamma=$ the cyclic shear strain induced within the soil. The threshold shear strain is most often determined through experiments to determine seismic liquefaction potential therefore uncertainty with the application of the threshold shear strain to the problem of wave-induced pore pressure must be addressed. For instance, the threshold shear strain is typically determined using 10 to 30 loading cycles to be consistent with earthquakes; however, the number of wave loading cycles in an ocean storm event will be orders of magnitude higher than in an earthquake.

Studies suggest, however, that the number of loading cycles has little influence on the measured threshold shear strain (Erten and Mayer, 1995; Hsu and Vucetic, 2006; Hazirbaba and Rathje, 2009). Secondly, experiments are performed under much higher stress levels than what is experienced in the upper strata of the seabed. The concept of the threshold shear strain is novel in that it is independent of confining stress; therefore, the uncertainty in adjusting relatively higher stress levels used for seismic based experiments to much lower confining stresses related to the problem of ocean wave-induced pore pressure (commonly known as $\mathrm{K}_{\sigma}$ effect) is unnecessary. Therefore it is assumed that the existing database of threshold shear strain values determined for the purposes of seismic pore pressure evaluation can be applied to the problem of ocean wave liquefaction. 


\section{Estimation of Cyclic Shear Strain}

Cyclic shear stresses induced in the seabed result from the dynamic loading of the seabed surface due to harmonic water-waves. The amplitude of the pressure on the seafloor from linear wave theory is shown below (Finn et al. 1983),

$$
p_{o}=\frac{\gamma_{w} H}{2 \cosh (k d)}
$$

where $\gamma_{\mathrm{w}}=$ unit weight of water, $\mathrm{k}=$ wave number $(=2 \pi / \lambda$ where $\lambda$ is the wavelength $)$, $\mathrm{d}=$ still water depth, $\mathrm{H}=$ wave height. The horizontal and vertical cyclic shear stresses in an elastic half space is proportional to the amplitude of the bottom pressure and thus may be described by a shear influence factor,

$$
\tau_{h}=p_{o} I
$$

where $\tau_{h}=$ shear stress on the horizontal and vertical planes, and $I=$ shear stress influence factor. Fung (1965) derived an analytical solution of the horizontal shear stress for any depth within a homogenous elastic half space subjected to a sinusoidal loaded bottom pressure. This solution expressed as an influence factor is as follows:

$$
I=k z \exp (-k z)
$$


The use of a cyclic horizontal shear stress is consistent with previous stressbased ocean wave liquefaction procedures (e.g. Seed and Rahman 1978; Clukey et al. 1983; Nataraja and Gill 1983; Finn et al. 1983). However, the stress path of ocean wave loading has been shown to be more damaging than for direct simple shear due to the rotation of principle stresses (Ishihara and Towhata, 1983). It is also important to note that seabed conditions experienced in the marine environment are most often not homogenous and therefore will produce uncertainty to Equation 4. To address this issue, a linear elastic finite element analysis is later presented to determine influence factors of more realistic seabed conditions in the marine environment (i.e. layered, linear increasing shear modulus profiles).

The cyclic shear strain induced in the seabed $(\gamma)$ can be expressed through the shear modulus of the soil,

$\gamma=\frac{\tau_{h}}{G}$

where $\tau_{h}=$ the horizontal cyclic shear stress induced in the seabed and $G=$ the secant shear modulus.

The stress-strain behavior of a soil under cyclic loading is nonlinear even below the threshold shear strain level and thus an equivalent linear analysis is used to estimate shear strains. The secant shear modulus $(G)$ is defined as:

$$
G=G_{o}\left[\frac{G}{G_{o}}\right]_{\gamma}
$$


where $G_{o}=$ small strain shear modulus, $\left[G / G_{o}\right]_{\gamma}=$ the modulus degradation factor which is dependent upon the level of cyclic shear strain amplitude. By substituting Equation 3 and 6 into Equation 5, the shear strain induced in the seabed can be rewritten in the following general form.

$$
\gamma=\frac{p_{o} I}{G_{o}\left[G / G_{o}\right]_{\gamma}}
$$

To calculate the shear modulus from Equation 7, the measurement of the small shear strain modulus, $G_{o}$, is required and is related to shear wave velocity,

$$
G_{o}=\rho V_{s}^{2}
$$

where $V_{s}=$ shear wave velocity, $\rho=$ total density of the soil. Numerous in-situ methods have been proposed to measure the shear wave velocity profile in the marine environment (e.g. cross-hole, down-hole, and inversion techniques). In-situ techniques are most often preferred in the marine environment because of the difficulty or near impossibility of collecting undisturbed samples in the upper strata of the seabed. Moreover, correlating the shear wave velocity to the small strain shear modulus is often the most accurate assessment of $G_{o}$ since other methods (i.e. standard penetration tests (SPT), cone penetration tests (CPT), etc.) are highly uncertain or impractical. Non-destructive methods have been developed in recent years utilizing a 
spectral analysis of surface waves approach (SASW) to measure the shear wave velocity profile in the seabed (Rosenblad, 2000). Later, this paper uses data obtained from a field test where a multichannel analysis of surface waves (MASW) approach was used to collect the in-situ shear wave velocity profiles. Although to the author's knowledge the accuracy of MASW (or other in-situ methods) has not been studied under these low confining stresses for the upper strata of the seabed, the analysis will illustrates the application of the model by incorporating a non-destructive approach like MASW.

If in-situ measurements of the shear wave velocity cannot be obtained or if the properties of an underwater fill have to be estimated before it is placed the following empirical relationship may be considered for normally consolidated soils (Hardin and Black, 1968; Hardin, 1978):

$G_{o}=\frac{625}{0.3+0.7 e^{2}} \sqrt{p_{a} \sigma_{m}{ }^{\prime}}$

where $e=$ void ratio, $\sigma_{m}{ }^{\prime}=$ mean effective confining pressure, and $p_{a}=$ reference pressure in the same units as $G_{o}$ and $\sigma_{m}{ }^{\prime}$. The mean effective confining pressure can be given as $\sigma_{\mathrm{v}}{ }^{\prime}\left(1+2 \mathrm{~K}_{\mathrm{o}}\right) / 3$; where $\sigma_{v}{ }^{\prime}=$ the vertical effective stress and $K_{o}=$ lateral earth pressure coefficient. Equation 7 is derived from resonant column tests for clays and sands and represents an average relationship. Moreover, it has been shown that for sands under low strains (less than $10^{-4}$ ), $\mathrm{G}_{\mathrm{o}}$ is strongly dependent on void ratio and confining stress and nearly independent of soil fabric (Hardin and Black, 1968). 
Numerous modulus degradation curves have been proposed in the literature for the purpose of modeling site response in earthquake engineering. The authors prefer the degradation curve from Ishibashi and Zhang (1993) because it is based on an extensive soil database and consider the effects of both mean effective confining stress and soil plasticity. The equations are listed below,

$$
\begin{aligned}
& {\left[\frac{\mathrm{G}}{\mathrm{G}_{\mathrm{o}}}\right]=\mathrm{K}\left(\sigma_{\mathrm{m}}{ }^{\prime}\right)^{\mathrm{m}}} \\
& K=0.5\left\{1+\tanh \left[\ln \left\langle\left(\frac{0.000102+n}{\gamma}\right)^{0.492}\right\rangle\right]\right\} \\
& n=\left\{\begin{array}{lll}
0 & \text { for } & I_{p}=0 \\
3.37 \times 10^{-6} I_{p}^{1.404} & \text { for } & 0 \leq I_{p} \leq 15 \\
7.0 \times 10^{-7} I_{p}{ }^{1.976} & \text { for } & 15 \leq I_{p} \leq 70 \\
2.7 \times 10^{-5} I_{p}^{1.115} & \text { for } & I_{p} \geq 70
\end{array}\right\} \\
& m=0.272\left\{1-\tanh \left[\ln \left(\left(\frac{0.000556}{\gamma}\right)^{0.4}\right)\right]\right\} \exp \left(-0.0145 I_{p}{ }^{1.3}\right)
\end{aligned}
$$

where $I_{p}=$ plasticity index. Since the modulus degradation factor depends on the level of cyclic shear strain, the factor must be determined iteratively. Currently, degradation curves do not account for the stress path of ocean wave loading and use a direct simple shear condition with symmetrical loading. Although this is consistent with previous assumptions made for this model, as well as, previous works from the 
literature, there will be higher degradation in a seabed subjected to water-wave loading due to the continuous rotation of principle stresses. Secondly, the degradation curves above do not consider the effects of pore pressure generation. However, since the model presented herein mostly deals with strain levels below the threshold shear strain, the curves are applicable.

\section{Estimation of Threshold Shear Strain}

In lieu of laboratory experiments on soil samples, the threshold shear strain may be selected from literature. The Hsu and Vucetic (2006) study compiled a large amount of cyclic tests that quantified the threshold shear strain for a range of soil types. These results are shown in Figure 2 and demonstrate that the threshold shear strain shows a strong correlation to plasticity index. The method only deals with strain levels less than the threshold shear strain thus a total stress analysis is applicable. It is important to note that these tests were conducted using undrained conditions; therefore, a selected value of the threshold shear strain to represent conditions in which soils are allowed sufficient time for drainage (i.e. wave-induced generated pore pressure) will result in conservatism. 
SHEAR STRESS INFLUENCE FACTORS FOR INHOMOGENEOUS SEABED

A finite element (FE) analysis was performed to investigate the shear stress profiles in an inhomogeneous elastic half space to more closely represent soil conditions often experienced in the field. This was accomplished be performing a linear elastic analysis to develop normalized cyclic shear stress charts for a twolayered profile and a profile having a linear increasing shear modulus with depth. The numerical simulations were performed using a commercial finite element program under plane strain conditions. The development of the FE model and the results are described below.

Development of Finite Element Models

The FE models had a width and a depth equal to twice the wavelength $(\lambda)$ in order to minimize boundary effects. This was based in part from trial and error as well as using Figure 4 as a basis to conclude that values of the shear stress at depths greater than one wavelength into the sediment bed are negligible. To best represent conditions seen in the field, boundary conditions of the models were unrestrained at the sediment surface, fixed in the horizontal direction on both side boundaries and fixed in both the horizontal and vertical directions along the bottom boundary.

The meshes of both models consisted of approximately 200 external nodes and elements of 4 nodal quadrilateral shape. The software program contained a built-in mesh generating function allowing for the most accurate and optimized mesh quality. Built-in mesh quality functions were also used for the software program to reinforce 
an accurate mesh. An external load representing that of water-wave loading (i.e. a sinusoidal shaped bottom pressure), was constructed on the free surface by using a triangular distribution that was discretized on the sediment surface into $\lambda / 32$ segments.

Before constructing the layered models, a homogeneous elastic model was constructed and the results were compared to the analytical solutions to validate the model output. Two models were then constructed to represent shear modulus profiles for a two-layered system and a linear increasing shear modulus with depth as shown in Figure 5. The numerical analyses were performed at different spatial scales to ensure that the shear stress plots could be normalized.

To encompass a range of potential Poisson ratio values, the numerical analyses were performed using three values of the Poisson ratio: 0.1, 0.3, and 0.49. A reasonable value of the Poisson ratio can be approximated by the level of strain or soil condition that best represents the problem of interest. Soils that experience small strains (i.e. $\mathrm{G}_{\mathrm{o}}$ ) typically range from 0.1 to 03 ; whereas, relatively larger strain levels (e.g. strains experienced near footings of shallow foundations) may range from 0.2 to 0.4 for drained conditions. The Poisson ratio for an undrained soil at large strains is theoretically 0.5 .

\section{Two-Layered Shear Modulus Profile}

The case of two distinct sediment layers is often experienced in the marine and lacustrine environment. For example, it is common practice to remediate hazardous sediments, protect buried sea cables, or mitigate habitats by placing a thick granular 
cap over soft sediments. This distinct difference among sediments for each layer will result in a different shear stress profile from the homogeneous solution.

The two-layered elastic model was described by two parameters: the thickness of the top layer, $\mathrm{T}$, and the ratio of the shear modulus of the top layer to the shear modulus of the bottom layer. The top layer thickness $(\mathrm{T})$ was modeled by constructing the interface between the two layers at normalized depths of $\lambda / 16, \lambda / 8$, $\lambda / 4, \lambda / 2,3 \lambda / 4$. Each of the layers was assigned homogeneous shear modulus values corresponding to the shear modulus ratios of $0.1,1.0$ and 10 to provide a range of possible values.

Figures 6 through 10 summarize the finite element results in the form of dimensionless charts. These figures all show similar trends: however, are dependent on the location of the layer interface relative to the depth of the maximum shear stress in the homogeneous case (i.e. G1/G2=1.0). As the depth of the interface gets closer to the depth of maximum shear stress in the homogenous case, the effect on the calculated shear stress becomes more pronounced. This is illustrated in Figure 7, for example, where the interface was close to the depth of the maximum shear stress in the homogeneous case. The maximum normalized shear stress was 0.70 in the upper layer as compared to 0.36 in the homogeneous case. As expected as the thickness of the top layer gets very thin (i.e. $\mathrm{T} \rightarrow 0$ ) or very thick (i.e. $\mathrm{T} \rightarrow \infty$ ) than the finite element results approach the homogeneous solution.

The influence of the Poisson ratio is also more pronounced when the interface is close to the depth of the maximum shear stress for the homogeneous case. For example in Figure 7, a Poisson ratio of 0.49 corresponds to a shear stress value of 0.17 
and a Poisson ratio of 0.1 corresponds to a shear stress value of 0.35 at a depth just below the interface layer.

\section{Linear Increasing Shear Modulus Profile}

When normally consolidated marine deposits are encountered in the marine environment the shear modulus profile is often represented as a power function in which the initial portion of this relationship can be approximated as linear. For the purposes of this model, which deals with the upper strata of the seabed, a linear representation can be considered reasonable to characterize the shear modulus for normally consolidated to slightly overconsolidated seabed deposits.

To model a linearly increasing modulus profile with depth, the numerical domain was discretized into many thin layers (Figure 5) and a constant shear modulus was applied in each layer. The analysis used two parameters: $G_{i}$ and $G_{\lambda}$-which represent the shear modulus located at the free surface and one wavelength respectively. A range of values for the Poisson ratio were used in the numerical analysis; however, results showed no significant difference with varying values of the Poisson ratio; therefore, it was unnecessary to show a range of values for the Poisson ratio.

Different ratios of $\mathrm{G}_{\mathrm{i}} / \mathrm{G}_{\lambda}$ (designated as $\alpha$ ) are plotted in Figure 11. As expected, as $\alpha$ approaches a value of 1 , the shear stress profile will approach the homogenous solution. The shear stresses in the linearly increasing profile were lower than the homogenous case at normalized depths of less than 0.3 , and higher below this depth. The difference between the homogenous case and the case of a linearly 
increasing modulus profile are relatively small. For example, for an alpha of 0 , the maximum shear stresses are roughly $20 \%$ less than in the homogenous case (i.e. alpha $=1.0$ ). The results of this analysis allow the quick and accurate selection of the shear stress profile in the seabed from measured shear stress values and wave conditions. 


\section{ANALYSIS PROCEDURE}

Oceanographic data required for the analysis of wave-induced liquefaction is only available from deep water locations. If the analysis of a site is located within coastal waters, a probabilistic design deep water wave height and wave period must be calculated and propagated to near-shore environments. This process is beyond the scope of this paper and often requires using analyses that encompass phenomena such as shoaling, refraction, and diffraction for site-specific bathymetric terrain. Once the oceanographic parameters are obtained (wavelength, wave number, wave height, still water depth) the following description is meant to serve as a general guideline to implement the model. Figure 1 is a schematic of the parameters involved.

The model is based on the comparison of the threshold shear strain to the induced cyclic shear strain in the seabed to determine a factor of safety against pore pressure generation at a specified depth below the seafloor (Equation 1). To determine these factors, a site investigation is required to obtain information on soil types, plasticity index, and small strain shear modulus profiles for one wavelength depth into the seabed.

First, the threshold shear strain is selected at the specified depth from Figure 3 and the measured plasticity index of the soil.

Next, the induced shear strain is calculated at the specified depth using the generalized Equation 7. This requires the estimation of the cyclic shear stress that is based on the anticipated modulus profile at the site of interest. Therefore, it is recommended that a $G_{o}$ profile be developed first to guide the selection of the 
appropriate influence factor. For example, if the shear modulus profile is approximately constant with depth than Equation 4 may be applicable.

The calculation of induced shear strain also depends on the modulus degradation that is a function of shear strain. Therefore, an iterative procedure must be used as follows:

1) Assume a value of $\left[G / G_{0}\right]$.

2) Calculate a shear strain from Equation 7 using $\left[\mathrm{G} / \mathrm{G}_{\mathrm{o}}\right]$ from step 1 .

3) Calculate $\left[G / G_{o}\right]$ from Equation 10 using the strain calculated in step 2.

4) Compare the assumed and calculated values of $\left[\mathrm{G} / \mathrm{G}_{\mathrm{o}}\right]$.

5) Adjust the assumed value of $\left[G / G_{o}\right]$ and repeat the steps until the assumed and calculated values match.

The above process can be repeated for various depths in the seabed to construct profiles of threshold shear strain and induced shear strain. These results are then used to calculate a factor of safety profile with factors of safety of less than one indicating the potential for excess pore pressure generation. 


\section{VALIDATION OF THE STRAIN-BASED PROCEDURE}

A compilation of existing wave tank experiments was investigated to validate the strain-based procedure. Only one wave tank experiment with a known shear modulus was found (Clukey et al. 1985) and therefore was used in comparison to the model. A general description of the wave tank experiment, modeling details, and a comparison of the results are discussed below. For further details on the experimental procedures refer to Clukey et al. (1985).

\section{Wave tank parameters}

Figure 12 displays the dimensions of the wave tank used in the experiment. The wave tank is $17.1 \mathrm{~m}$-long, $0.76 \mathrm{~m}$-wide, and $0.91 \mathrm{~m}$-deep in the main section of the tank. The middle of the wave tank houses a $4.57 \mathrm{~m}$-long and $0.84 \mathrm{~m}$-deep sediment basin. Three test runs were selected from the experiment to compare to the model: Test 7-1, 7-2, \& 7-3 (adopting the same notation of Clukey et al.). The three tests ranged in wave heights from $0.9 \mathrm{~m}$ to $0.23 \mathrm{~m}$ and contained a constant water depth of $0.53 \mathrm{~m}$. Pore pressure transducers were embedded at various depths within the sediment basin to measure excess pore pressure and it was observed that minimal to intense liquefaction occurred for each of the sequential tests. Table 1 summarizes the wave conditions and measurements of pore pressure ratios, $r_{u}$, for each test - where the pore pressure ratio is defined as the excess pore pressure, $\Delta u$, divided by the effective overburden stress, $\sigma_{v}^{\prime}$. 


\section{Silt Properties}

The wave tank experiment was conducted on Danby silt which can be characterized as a late Pleistocene glacial outwash deposited during the last ice epoch in a lacustrine environment (Clukey et al., 1983). The silt was prepared in the wave tank by pumping slurry through a hydraulic line after which the silt was allowed to settle in the sediment basin. The shear modulus of the silt was measured from results obtained by a simple shear test conducted on Yukon silt - which contains similar grain characteristics to Danby silt. The simple shear test was conducted at an initial vertical effective stress of $7 \mathrm{kPa}$ and corresponds to approximately $0.7 \mathrm{~m}$ of overburden - which falls within the range of the wave tank's sediment basin. Since the shear modulus was obtained from similar silt and overburden stress, it can be concluded with reasonable confidence that the measurement of the shear modulus is an accurate representation of the Danby silt.

\section{Modeling Procedure}

The wave lengths of the wave tank experiments were observed to be much greater than the depth of the silt basin and therefore the role of boundary effects was anticipated to be of significant influence to the shear stress profile. The shear stress calculation would also be influenced by the modulus profile that is anticipated to increase with depth. To account for these conditions, a numerical model of the wave tank was constructed to calculate the shear stress profile for each test (Figure 13). Boundary conditions of the models were unrestrained at the sediment surface, fixed in the horizontal direction on both side boundaries and fixed in both the horizontal and 
vertical directions along the bottom boundary. These boundary conditions are consistent with previous models constructed in this paper.

The selection of a linear increasing shear modulus profile (with alpha value equal to zero) to represent the sediment basin was based on experimental measurements of the shear modulus for silt and sand (Figure 14). Figure 14 demonstrates a linear trend of the shear modulus for the filter sand and is within the range of confining stresses for the sediment basin. The finite element calculations of the shear stress profiles for each of the wave tank experiment tests is shown in Figure 15. Figure 15 shows dissimilar shear stress profiles than what would be anticipated for a homogeneous elastic half space and further confirms that boundary effects and an inhomogeneous shear modulus are a significant influence for the wave tank experiments. From the shear stress and shear modulus calculations above, Equation 5 was used to determine the induced shear strain within the sediment for each test. The determination of the threshold shear strain could not be found experimentally therefore Figure 3 was used to select an appropriate value of the threshold shear strain. Figure 3 shows a band of threshold shear strain values and an average line. To best represent the silt used in the sediment basin, the average value of the threshold shear strain was selected for a non-plastic silt (i.e. PI $=0)$. Although it is reasonable to select an average value of threshold shear strain, the selection of the lowest threshold shear strain could also be deemed reasonable as a conservative approach. 


\section{Results}

Figure 16 compares the factors of safety for the model and pore pressure ratios for Test 7-1. Of the three tests, Test 7-1 contained the lowest wave height and was the only test which contained one measurement of no excess pore pressure in the basin. From Figure 16, the trend of measured excess pore pressure values and factors of safety from the model are similar. For example, as the excess pore pressure dissipates at a depth of approximately $0.66 \mathrm{~m}$, the factor of safety begins to trend above a value of 1.0. Although this trend is nearly exact for the measured shear modulus value (solid line), a 10\% range in the shear modulus (dotted line) was calculated to show the model's sensitivity to G. This range of sensitivity seems to be reasonable since it encompasses a relatively small band to the measured shear modulus.

Figures 17 and 18 compare the factors of safety for the model and pore pressure ratios measured for Tests 7-2 \& 7-3 respectively. In these two tests, the pore pressure transducers all measured excess pore pressures in the sediment and Test 7-3 contained relatively higher values than Test 7-2. Figures $17 \& 18$ also reflect similar trends as in Figure 16 by producing factors of safety less than one in the silt. In comparison of these two figures, Figure 18 shows relatively lower factors of safety than Figure 17 due to larger pore pressure ratios.

The actual value of $\mathrm{G}$ in the wave tank's sediment basin may be different than G obtained from DSS testing and therefore may produce uncertainties relating to: the use of different silts, the difference in stress path between ocean wave loading and direct simple shear, and the level of strain used in DSS testing. It should also be noted that with the exception for Test 7-1, the shear modulus would increase after each 
successive test due to the previous wave exposure; however, since Test 7-1 was first, and produces more significant trends to the model's validation, this effect is inconsequential. As for the uncertainties mentioned above, they should be considered relatively insignificant since the value of the shear modulus for the silt was represented with reasonable accuracy. This suggests that the model displays an excellent agreement between model and wave tank experiments. 


\section{CASE STUDY}

The strain-based procedure is used to screen for excess pore pressure in the seabed for a site located within the coastal waters of Rhode Island. A hypothetical scenario at the site considers the placement of a cap to overlay contaminated marine sediment and is considered both immediately after the cap is placed (short-term) and after consolidation of the substrate layer (long-term). The cap is designed to be $1.5 \mathrm{~m}$ thick and contains a total unit weight of $19 \mathrm{kN} / \mathrm{m}^{3}$, a friction angle of $32^{\circ}$, and void ratio of 0.8 . The 20 year design sea state for the shelf waters of Rhode Island has a significant wave height $\mathrm{H}_{\mathrm{s}}=1.2 \mathrm{~m}$, peak wave period $\mathrm{T}_{\mathrm{p}}=4.5 \mathrm{~s}$ and a still water depth of $2 \mathrm{~m}$ at the site.

A field test was conducted in February 2013 in which shear wave velocity profiles were obtained using a multichannel analysis of surface waves (MASW) approach (Giard, 2013). MASW is a non-invasive inversion technique that measures interface waves (Scholte waves) between the water-sediment boundary and are closely related to the shear wave speed and attenuation for 1-2 wavelengths in the seabed. A pre-existing boring $\log$ at the location of the measured shear wave velocity profiles confirms that the site is composed of organic marine silt.

Referring back to the section on the model's implementation, a simple systematic approach can be used to screen for excess pore pressure at the site under short and long term conditions. The calculation of the shear stress profile is determined by first representing the site as a two layered system. This requires both the determination of the shear modulus ratio $(\mathrm{G} 1 / \mathrm{G} 2)$ and the top layer thickness, $\mathrm{T}$. The shear modulus ratio was determined from Figure 19 which plots the small strain 
shear modulus profiles for the cap and silt layers under short and long term scenarios. Equation 9 was used with the given cap properties to determine $\mathrm{G}_{\mathrm{o}}$ in the cap layer. The small strain shear modulus for the silt layer in the long term was calculated by increasing the effective stress by the amount due to the cap. Using Figure 19, it was estimated that the shear modulus ratio was 0.4 for the short term and 0.32 for the long term by selecting an approximate average value for each of the layers respectively. Since both the short and long term shear modulus ratios lie between the calculated values seen from the non-dimensional charts (Figures 6 - 10), the shear stress profile must be interpolated. Also, the non-dimensional thickness of the cap is bounded between Figures $6 \& 7$ - therefore Figure 6 was selected as conservative approximation of the shear stress profile due to slightly larger shear stress values within the substrate layer. A Poisson ratio of 0.3 was used in the calculation of the shear stress profile as a reasonable representation of the soil. From Figure 6 it can be seen that a higher and lower value of the Poisson ratio would result in a higher shear stresses for the top and lower layers respectively. Using these higher shear stress profiles could be implemented into the analysis procedure in order to conduct a more conservative analysis.

The shear modulus was iteratively calculated using the steps outlined to calculate the shear strain in the seabed. Lastly, an average value of the threshold shear strain was selected from Figure 3 to compare to the shear strain. This comparison is shown in Figure 20 which shows the factor of safety against excess pore pressure in the seabed under short and long term conditions. 
The short term analysis shows that the factor of safety against excess pore pressure is less than one between depths $1.1 \mathrm{~m}-2.8 \mathrm{~m}$. This range, which encompasses both the cap and silt layer, is consistent with two trends. First, Figure 6 shows that the range of depths corresponding to factors of safety less than are where the highest shear stresses occur. Secondly, Figure 19 shows that the top of the silt layer approaches a stiffness of zero.

The long term analysis shows factors of safety greater than one in both layers. This increase in safety against generation of pore pressure from the short term scenario was expected due to an increase of stiffness within the silt layer. The analysis also shows a slight increase in safety for the cap layer even though the stiffness is keep identical to the short term scenario. It is interesting to note that as a result of the stiffness in the silt layer increasing, it can absorb additional shear stresses and thus reduce the shear stress in the cap. 


\section{SUMMARY \& CONCLUSIONS}

A strain-based procedure was presented in this paper and provides a means to screen for the generation of wave-induced pore pressure in the seabed. The model can be used for a wide range of seabed conditions often experienced in the marine environment (i.e. normally consolidated, overconsolidated, two-layered seabed) and can incorporate non-invasive methods to measure the soil's shear modulus. The model was shown to strongly agree with results obtained from existing wave tank experiments. These results showed that the generation and non-generation of excess pore pressure in the seabed corresponded to factors of safety of less than and greater than one respectively. Lastly, a case study was presented to demonstrate the practical implementation of the strain-based procedure from field measurements of shear wave velocity offshore. The case study demonstrated the ability to analyze the potential for residual pore pressure generation for a sand cap placed on an organic silt deposit in both the short and long-term condition. 


\section{ACKNOWLEDGEMENTS}

This project was funded by the Rhode Island Water Resources Center (Project No. 0003270). The author would also like to thank Dr. Edward Clukey for sending his thesis during preparation of this manuscript. 


\section{LIST OF REFERENCES}

Bradshaw, A.S. (2012). "A Strain-Based Model to Screen for Residual Pore Pressures in Sediment Caps." Proceedings of the ASCE 2012 Geo-Congress, 4069-4078.

Clukey, E.C., Kulhawy, F.H., and Liu, P.L.-F. (1983). "Laboratory and field investigation of wave-sediment interaction.” Report on Grant CEE-8200272 to National Science Foundation Washington, D.C.

Clukey, E.C., Kulhawy, F.H., and Liu, P.L.-F. (1985). "Response of silts to wave loads: Experimental study," Strength testing of marine sediments, Laboratory and in-situ measurements, ASTM STP 883, R.C. Chaney and K.R. Demars, Eds., American Society for testing and materials, Philadelphia, 1985, pp. 381396.

Dobry, R., R. S. Ladd, F. Y. Yokel, R. M. Chung, and Powell, D. (1982). "Prediction of pore water pressure buildup and liquefaction of sands during earthquake by the cyclic strain method," NBS Building Science Series 138, National Bureau of Standards, Gaithersburg, Maryland: 150.

Erten, D. and Mayer, M.H. (1995). "Cyclic undrained behavior of silty sand. ” Soil Dynamics and Earthquake Engineering, 14, 115-123.

Fung, Y.C. (1965). Foundations of Solid Mechanics, Prentice Hall, New Jersey, p. 195-197.

Finn, W.D.L., Siddharthan, R., and Martin, G.R. (1983). "Response of seafloor to ocean waves." Journal of Geotechnical Engineering, ASCE, 109 (4), 556-572.

Giard, J.L. (2013). "An inversion scheme for the shear wave speed using scholte wave dispersion.” Masters. Thesis. University of Rhode Island: U.S.

Hardin, B.O. (1978). "The nature of stress-strain behavior of soils." Proceedings of the ASCE Geotechnical Engineering Division Specialty Conference on Earthquake Engineering and Soil Dynamics, Vol. 1, 3-90.

Hardin, B.O. and Black, W.L. (1968). "Vibration modulus of normally consolidated clay." Journal of the Soil Mechanics and Foundation Division, ASCE, 94(2), 353-369. 
Hazirbaba, K. and Rathje, E.M. (2009). "Pore Pressure of silty sands due to induced cyclic shear strains." Journal of Geotechnical and Geoenvironmental Engineering, ASCE 135(12), 1892-1905.

Hsu, C.-C. and Vucetic, M. (2006). Threshold shear strain for cyclic pore-water pressure in cohesive soils. Journal of Geotechnical and Geoenvironmental Engineering, ASCE, 132(10), 1325-1335.

Ishibashi, I. and Zhang, X. (1993). "Unified dynamic shear moduli and damping ratios of sand and clay." Soils and Foundations, 33(1), 182-191.

Ishihara, K. and Towhata, I. (1983). "Cyclic response to rotation of principal stress directions as induced by wave loads." Soils and Foundations, 23(4), 11-26.

Ishihara, K. and Yamazaki, A. (1984). "Analysis of wave-induced liquefaction in seabed deposits of sand." Soils and Foundations, 24(3),85-100.

Lee, K.L. and Focht, J.A. (1975). "Liquefaction potential at Ekofisk Tank in North Sea,” Proc. ASCE, Vol. 101, GT1, pp. 1-18.

Nataraja, M.S. and Gill, H.S. (1983). "Ocean wave-induced liquefaction analysis." Journal of Geotechnical Engineering, 109(4), 573-590.

Rosenblad, B.L. (2000). "Experimental and theoretical studies in support of implementing the spectral-analysis-of-surface-waves (sasw) method offshore," Ph.D. dissertation, University of Texas at Austin, August 2000.

Seed, H.B. and Rahman, M.S. (1978). "Wave-induced pore pressure in relation to ocean floor stability of cohesionless soils.” Marine Geotechnology, 3(2), 123150.

Seed, H.B., Tokimatsu, K., Harder, L., and Chung, R. (1985). " Influence of SPT Procedures in Soil Liquefaction Resistance Evaluations.” J. Geotech. Engrg., 111(12), 1425-1445.

Sumer, B. Mutlu, and Jørgen Fredsøe. The Mechanics of Scour in the Marine Environment. River Edge, NJ: World Scientific, 2002. 445-503. Print. 


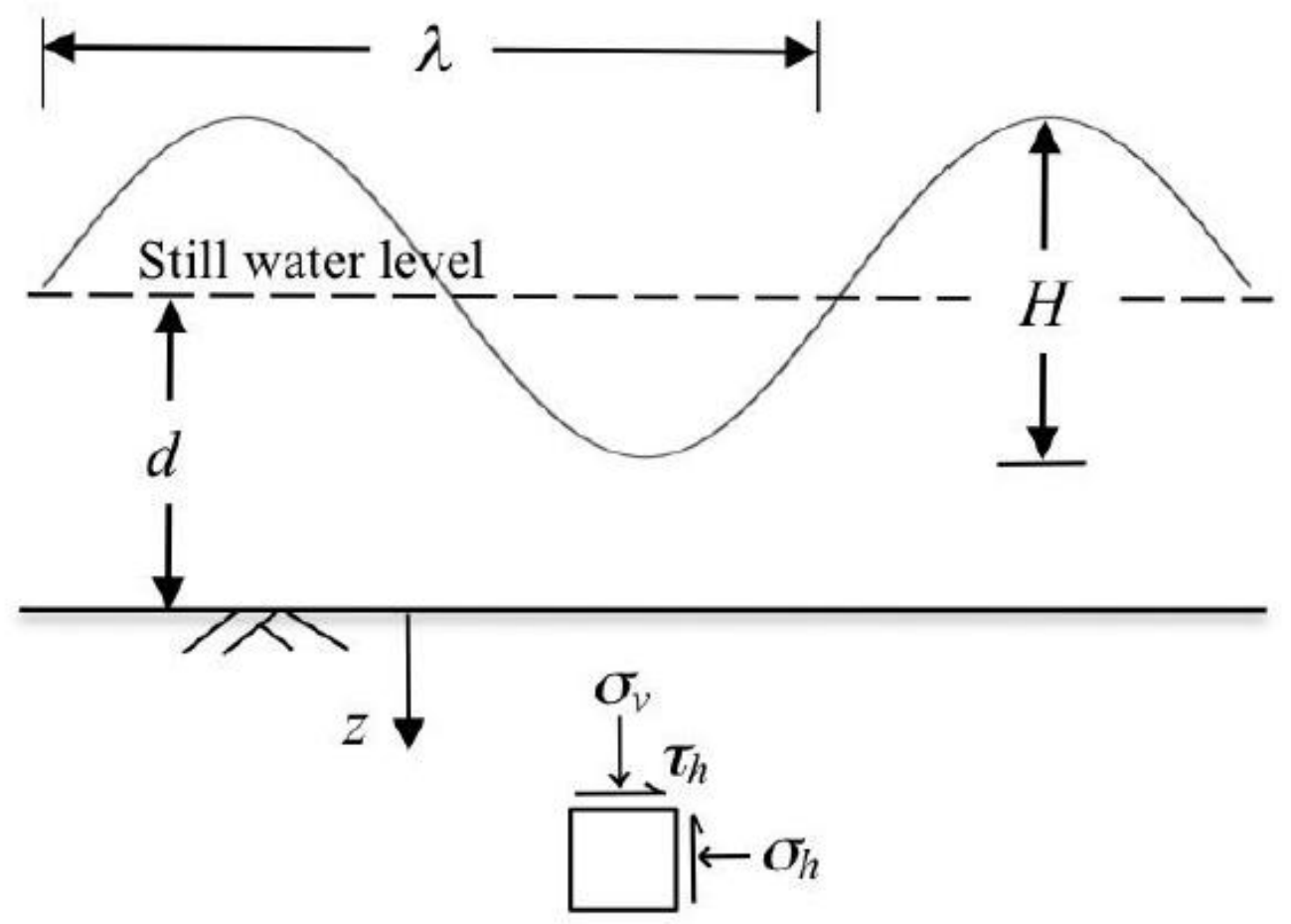

FIG. 1. Schematic of water-wave loaded seabed (Bradshaw 2012). 


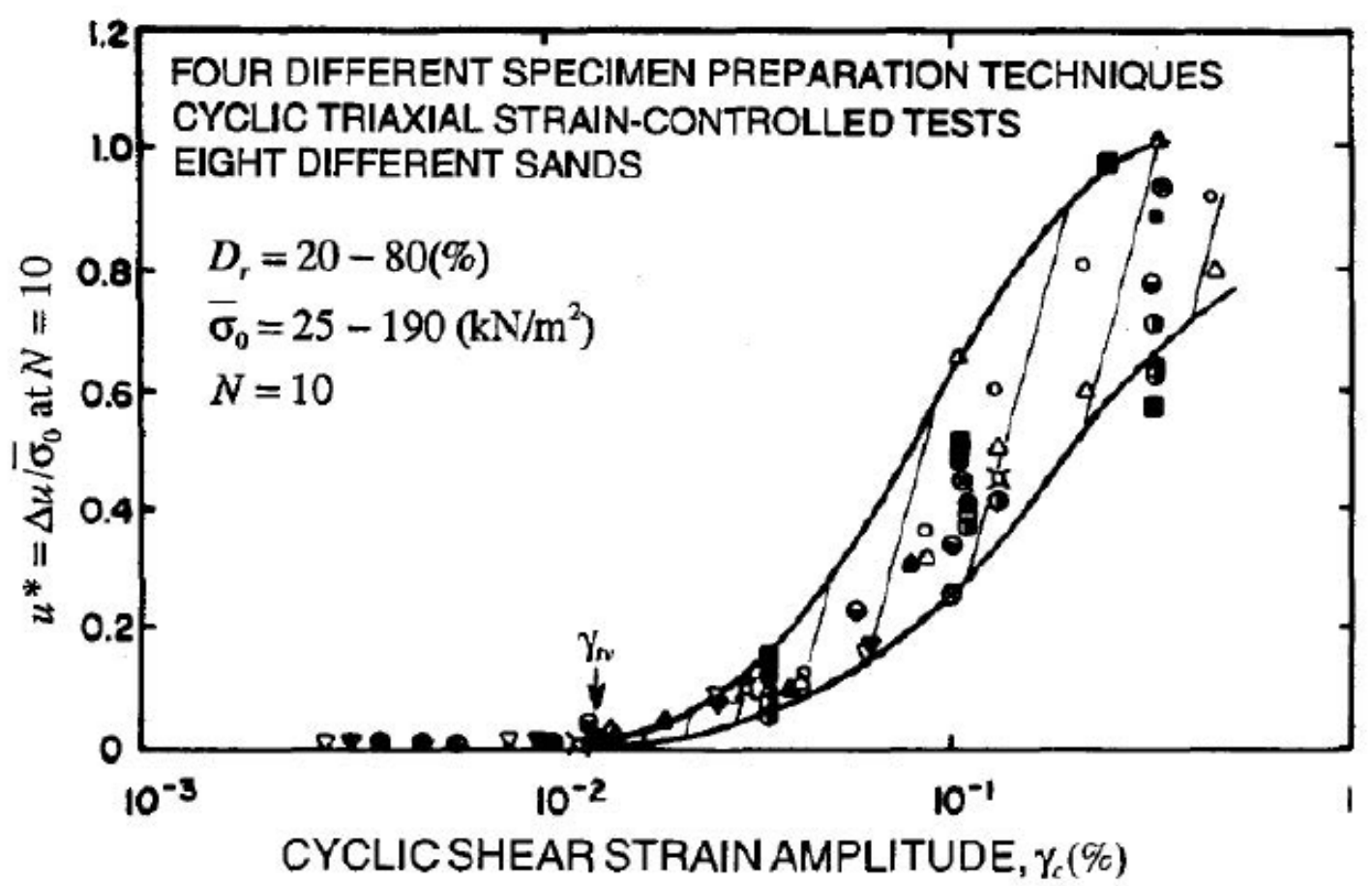

FIG. 2. Pore pressure ratios generated in a variety of sands under cyclic loading (Vucetic, 1994 after Dobry et al. 1982). 


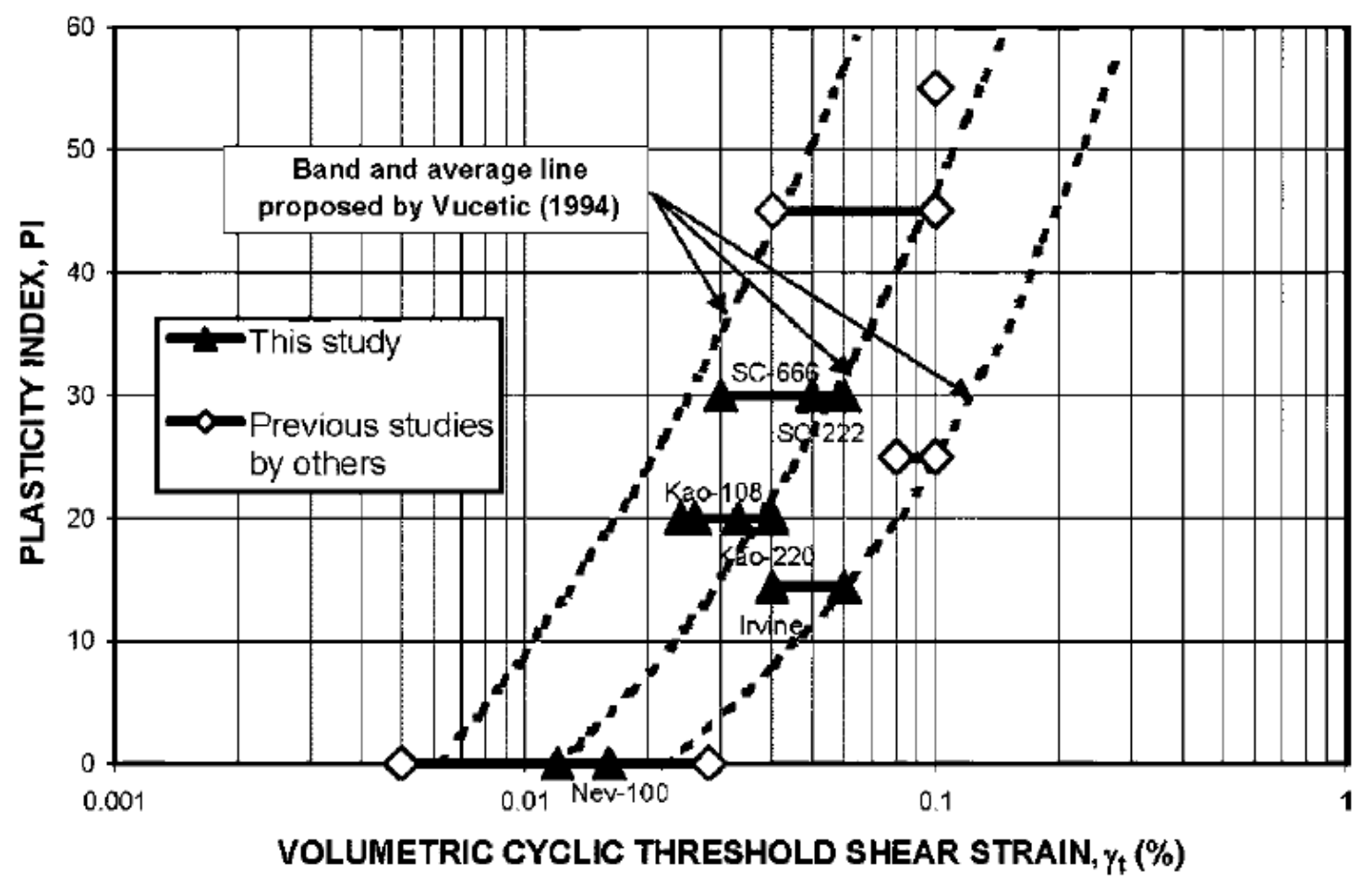

FIG. 3. Effect of plasticity index on threshold shear strain for cyclic porewater pressure (Hsu \& Vucetic, 2006). 


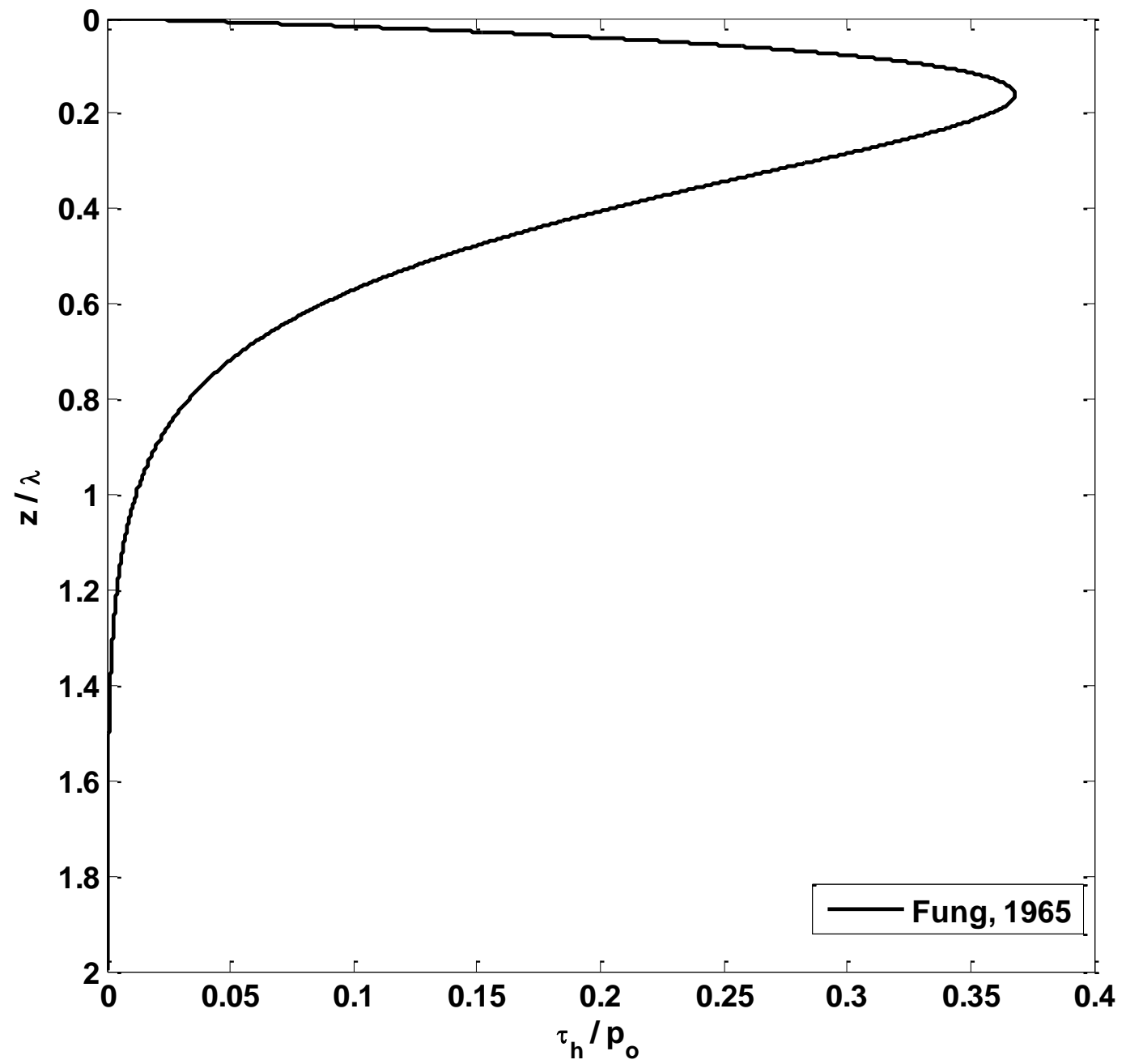

FIG. 4. Non-dimensional shear stress profile of analytical solution derived by Fung, 1965. 

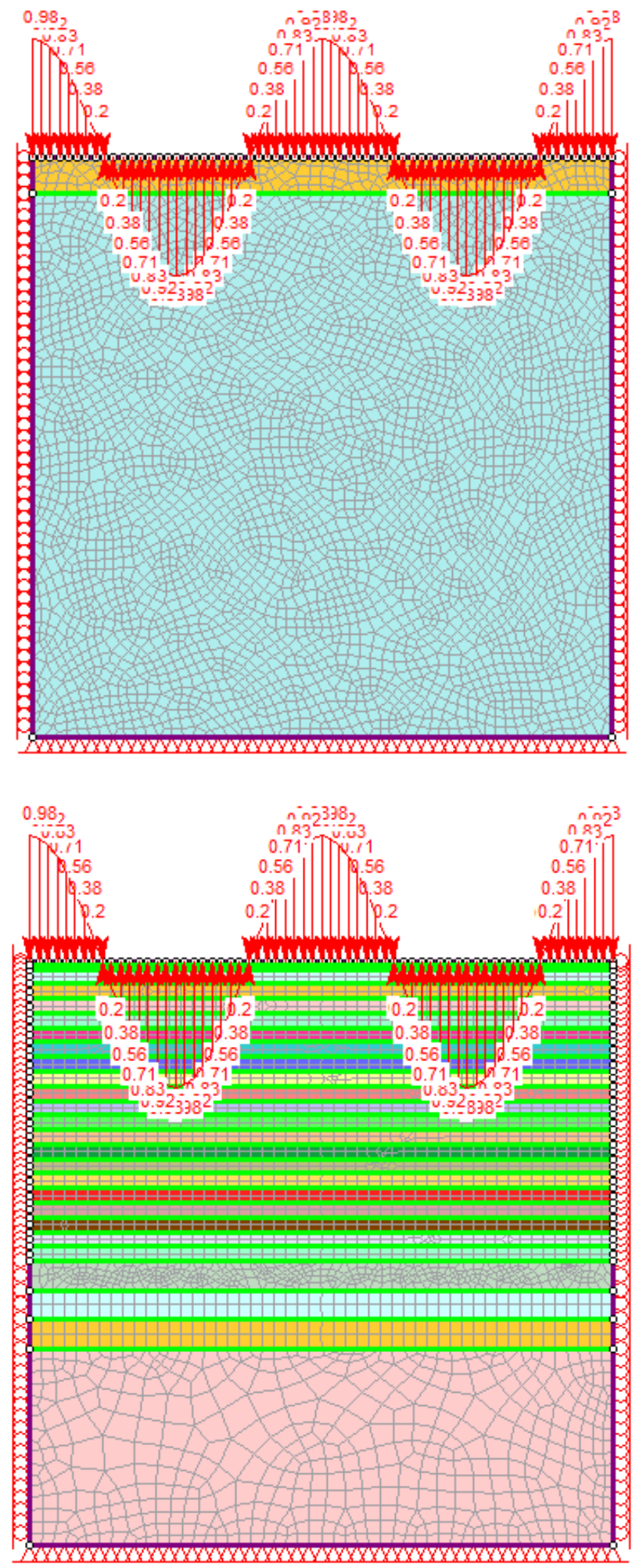

FIG. 5. Numerical models of two-layer (top) and linear increasing (bottom) shear modulus profiles. 


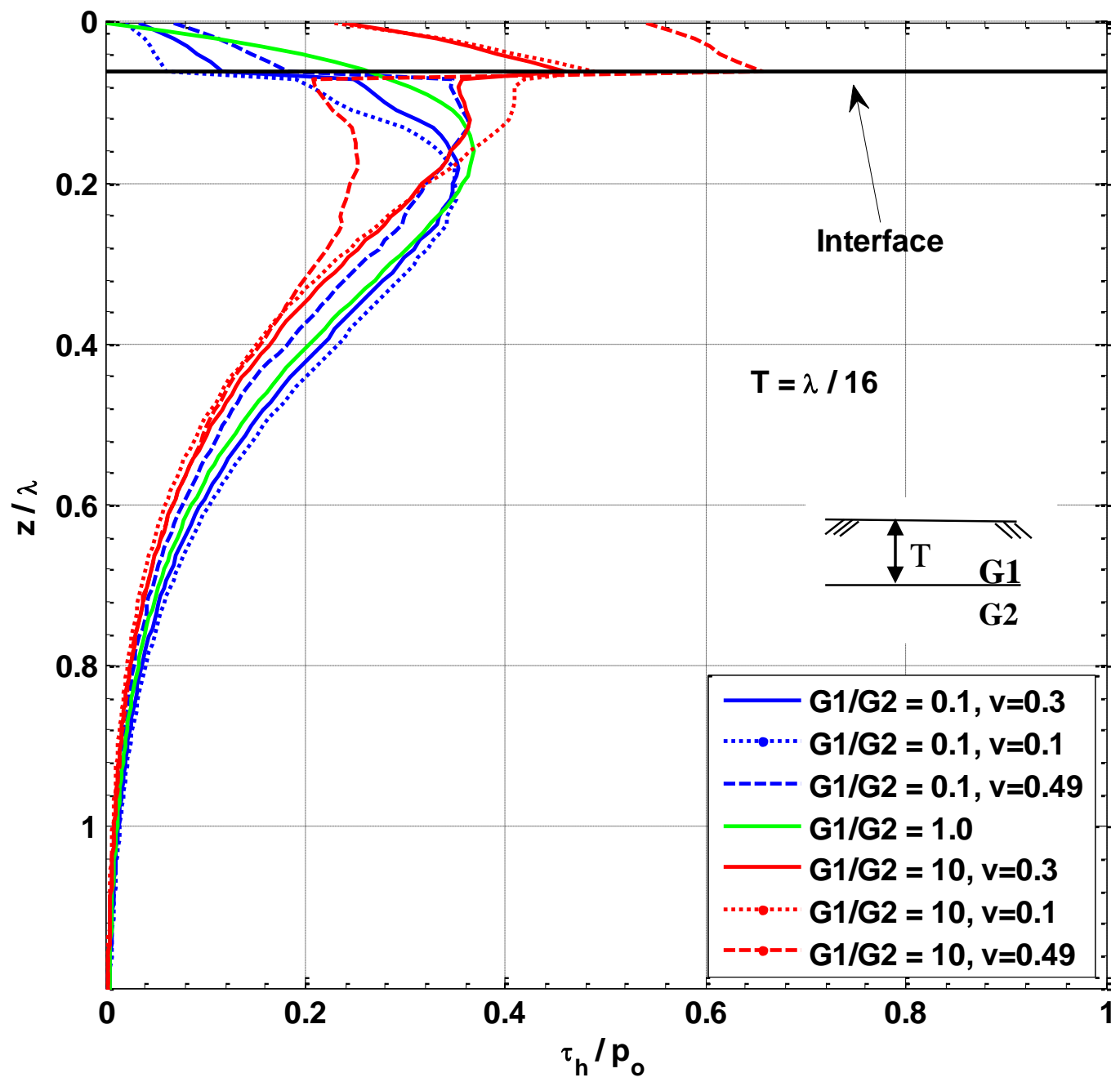

FIG. 6. Shear stress profile of a two layered seabed for different stiffness ratios, Top layer thickness $=\lambda / 16$. 


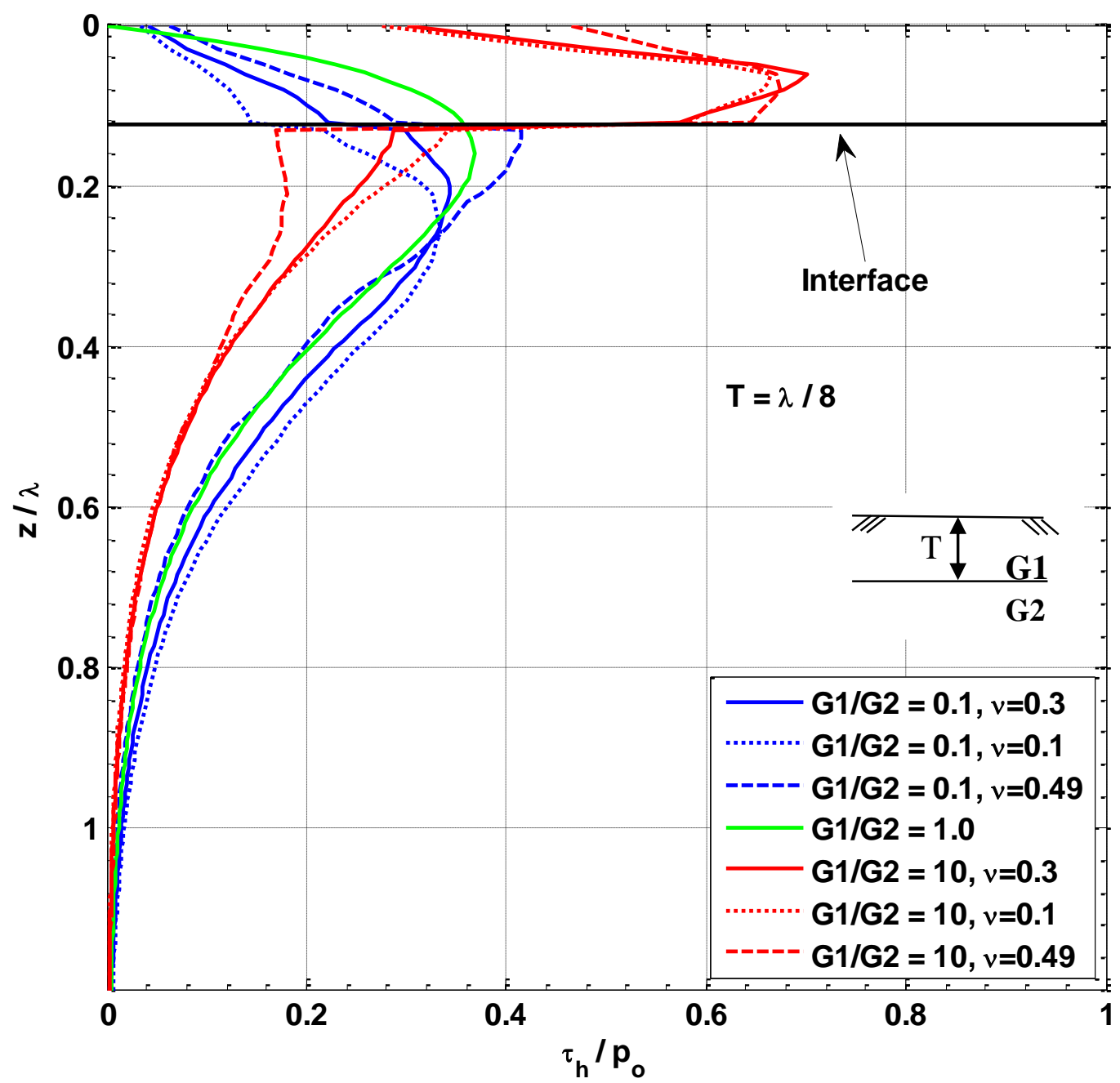

FIG. 7. Shear stress profile of a two layered seabed for different stiffness ratios, Top layer thickness $=\lambda / 8$. 


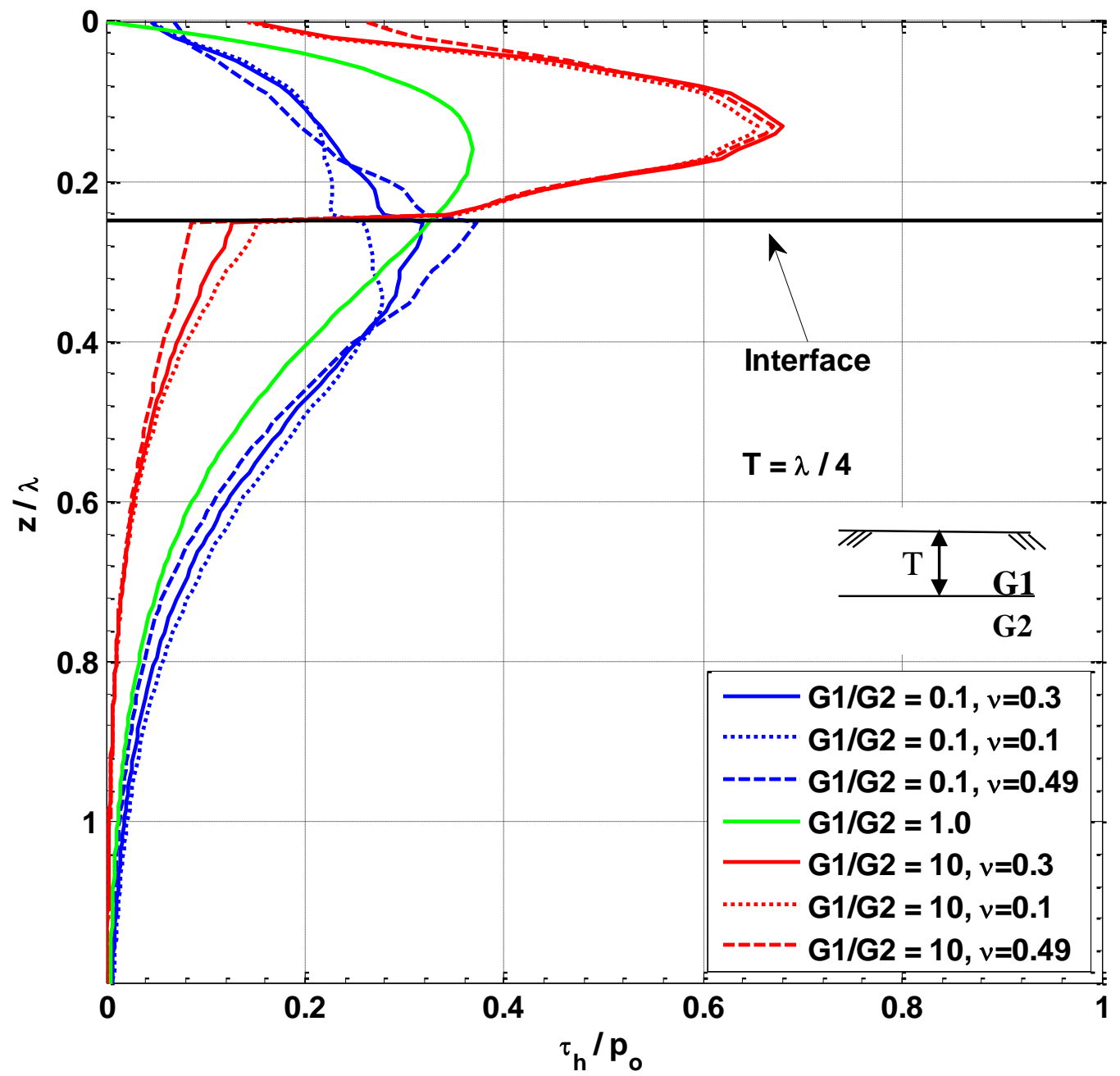

FIG. 8. Shear stress profile of a two layered seabed for different stiffness ratios, Top layer thickness $=\lambda / 4$. 


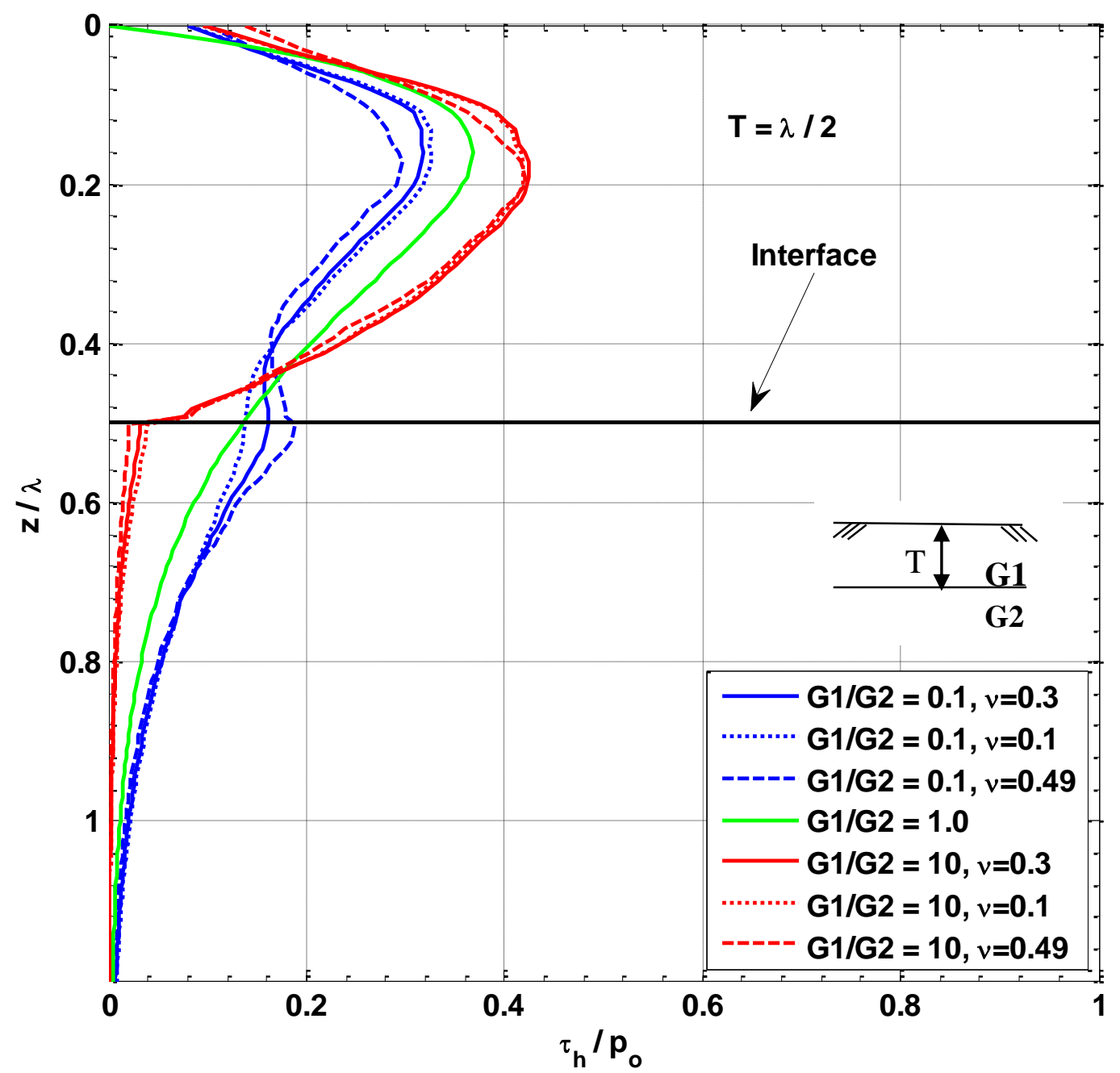

FIG. 9. Shear stress profile of a layered seabed for different stiffness ratios, Top layer thickness $=\lambda / 2$. 


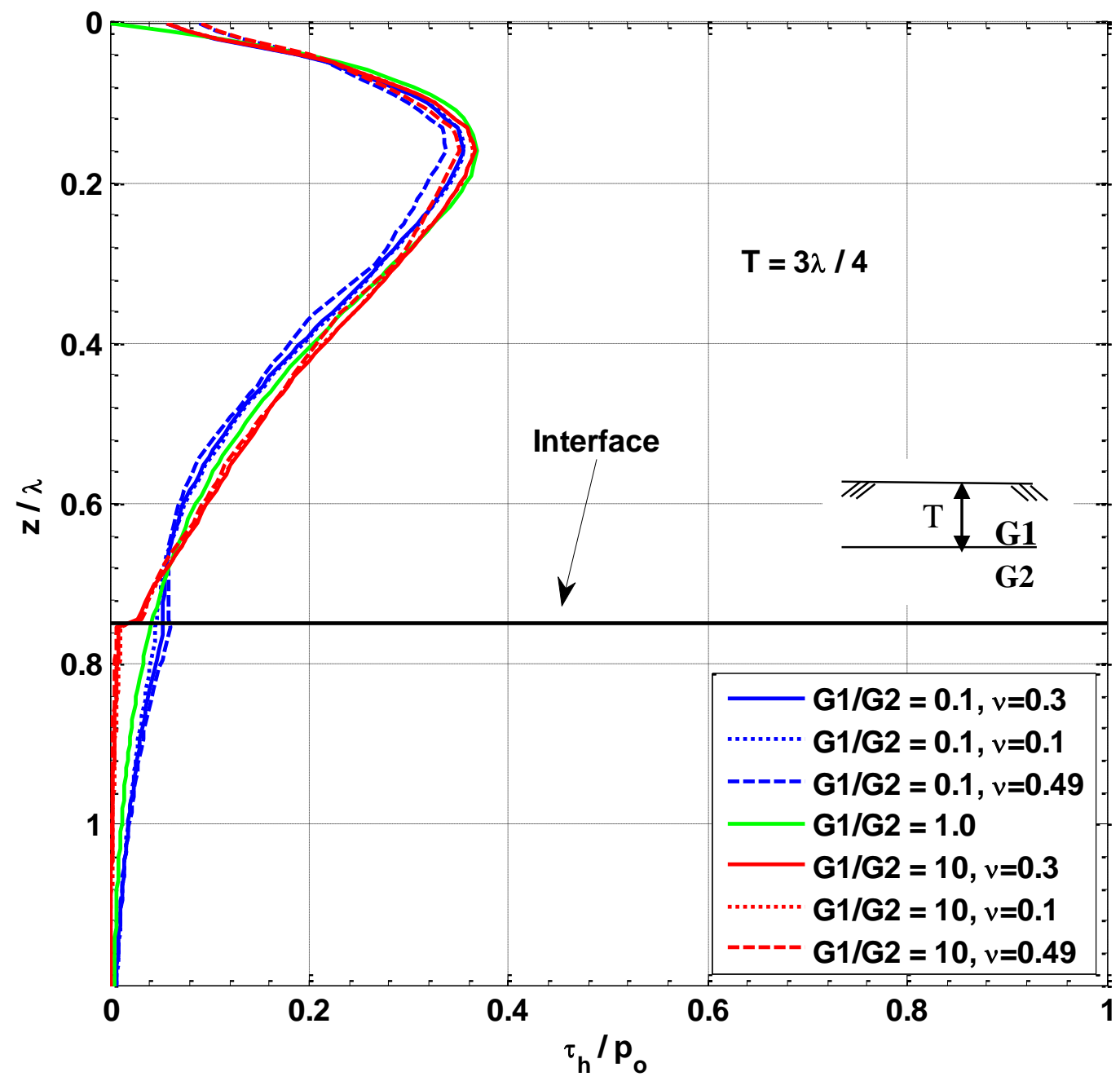

FIG. 10. Shear stress profile of a layered seabed for different stiffness ratios, Top layer thickness $=3 \lambda / 4$. 


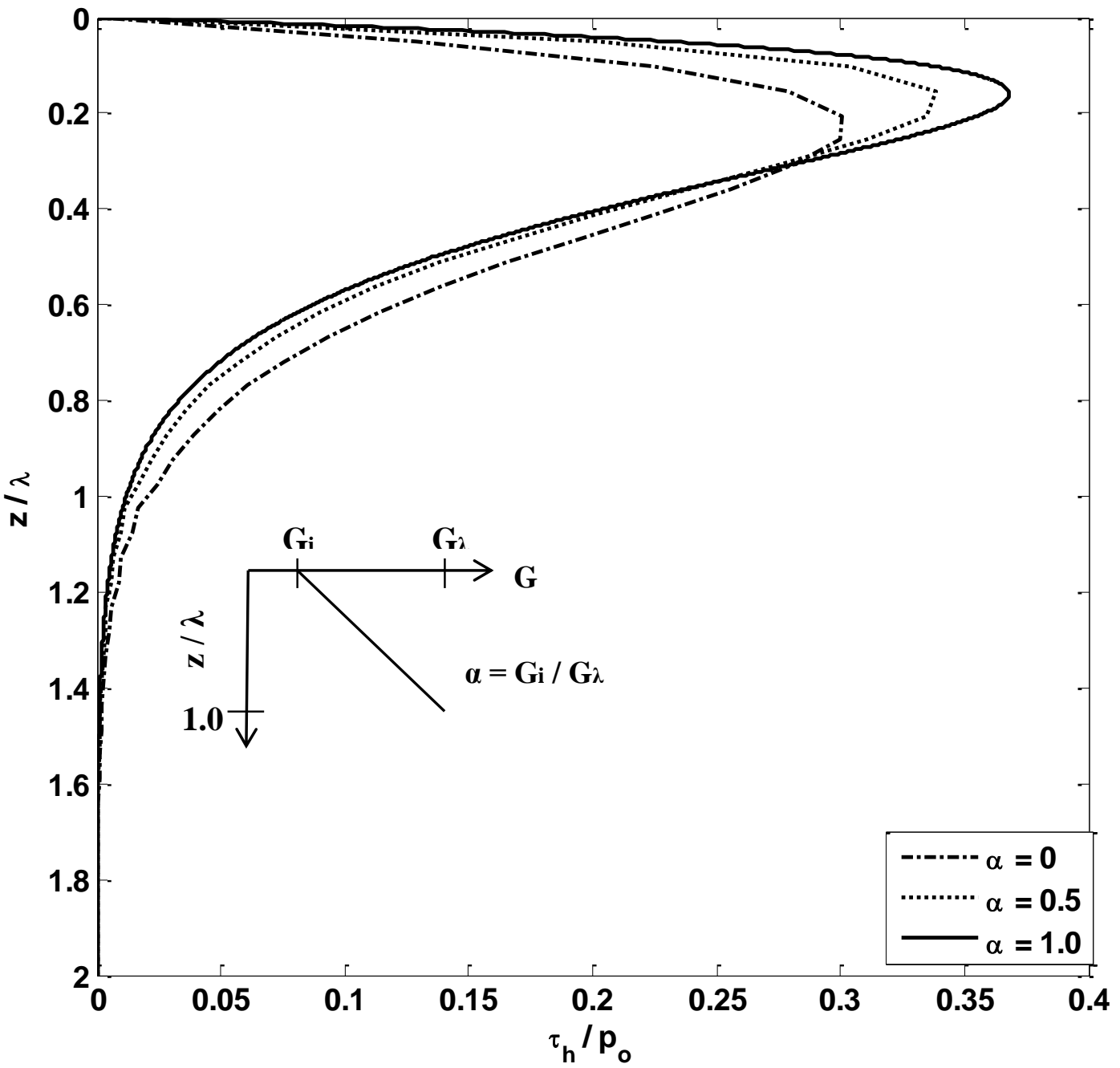

FIG. 11. Non-dimensional shear stress profile of linear increasing shear modulus. 


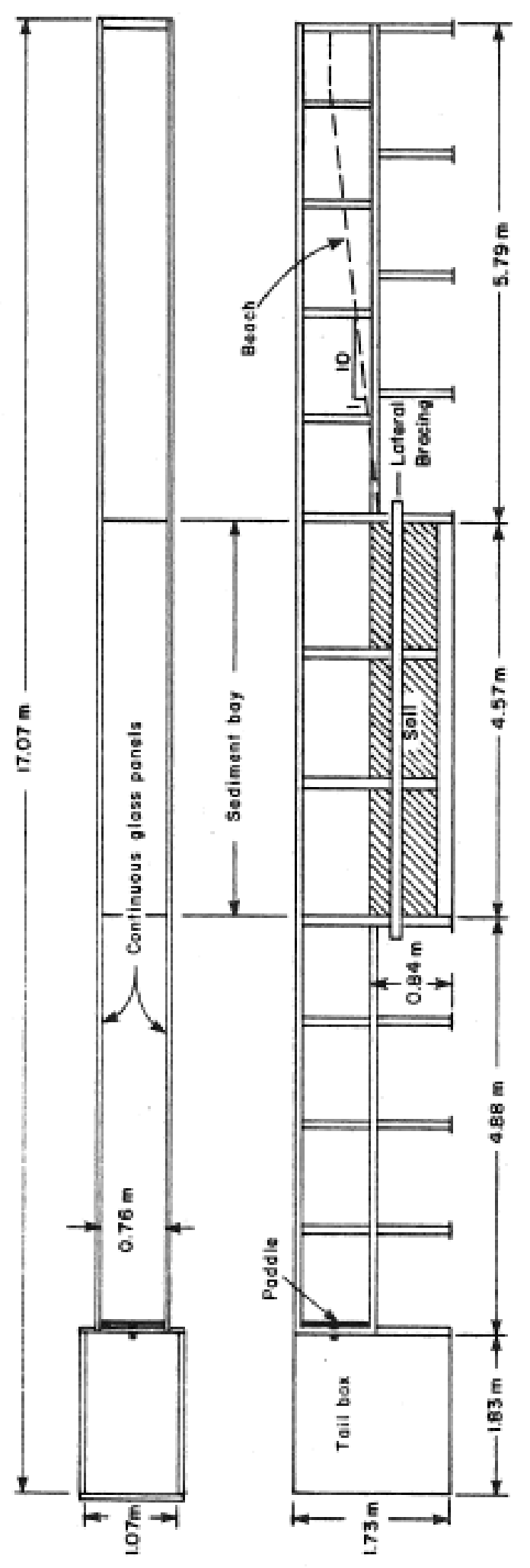

FIG. 12. Wave tank facility (Clukey, et al. 1985). 


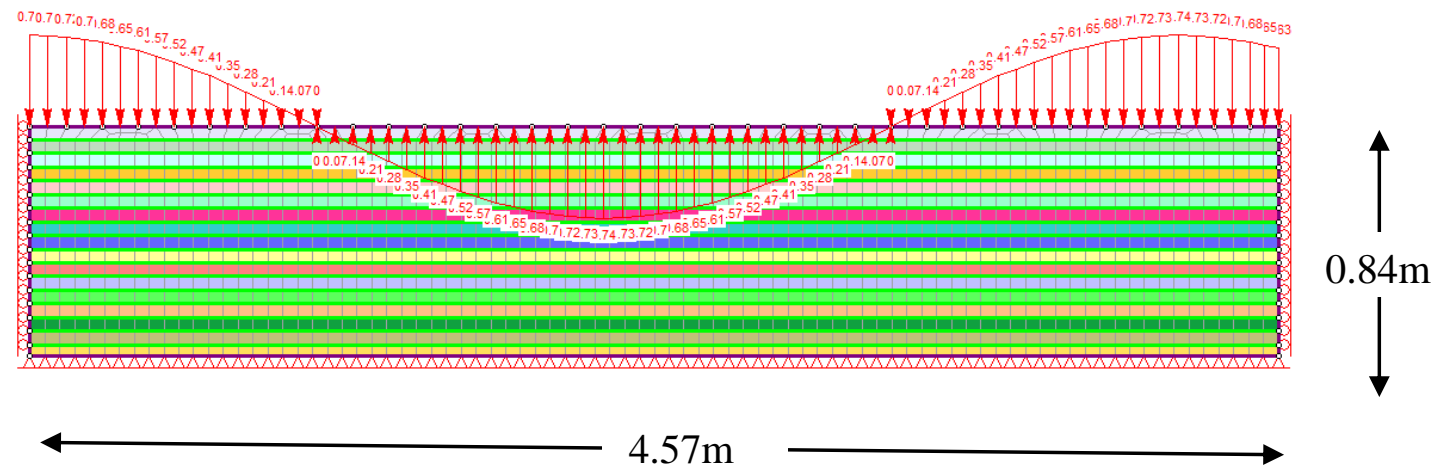

FIG. 13. Finite element model of wave tank facility. 


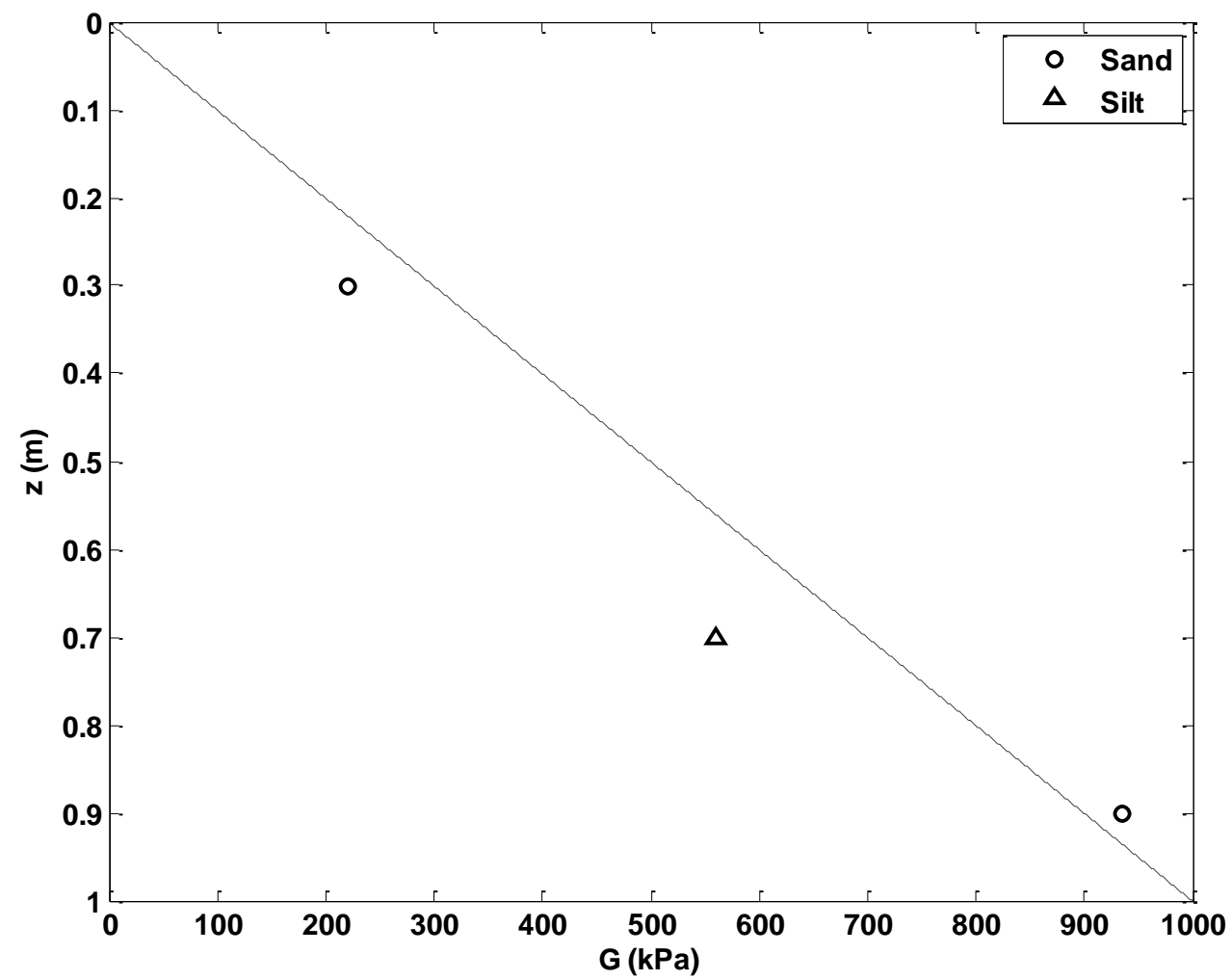

FIG. 14. Shear modulus measured in direct simple shear tests performed on Yukon Silt and Filter Sand under low confining stresses (data from Clukey et al. 1983). 
TABLE 1. - Wave parameters and results

\begin{tabular}{|c|c|c|c|c|c|}
\hline $\begin{array}{c}\text { Test } \\
\text { number }\end{array}$ & $\begin{array}{c}\text { Wave period } \\
\text { (s) }\end{array}$ & $\begin{array}{c}\text { Wave height } \\
\text { (m) }\end{array}$ & $\begin{array}{l}\text { Wave length } \\
\text { (m) }\end{array}$ & $\begin{array}{c}\text { Depth } \\
\text { (m) }\end{array}$ & $\begin{array}{c}\text { Pore-water } \\
\text { pressure } \\
\text { ratio, } \\
\mathbf{r}_{u}\end{array}$ \\
\hline $7-1$ & 1.76 & 0.09 to 0.10 & 3.55 & $\begin{array}{l}0.06 \\
0.23 \\
0.28 \\
0.62\end{array}$ & $\begin{array}{l}0.365 \\
0.277 \\
0.242 \\
0.069\end{array}$ \\
\hline $7-2$ & 1.79 & 0.15 to 0.16 & 3.63 & $\begin{array}{l}0.06 \\
0.23 \\
0.28\end{array}$ & $\begin{array}{l}0.832 \\
0.606 \\
0.773\end{array}$ \\
\hline $7-3$ & 2.02 & 0.20 to 0.23 & 4.20 & $\begin{array}{l}0.06 \\
0.23 \\
0.28 \\
0.62\end{array}$ & $\begin{array}{c}1.46 \\
0.761 \\
0.70 \\
0.385\end{array}$ \\
\hline
\end{tabular}




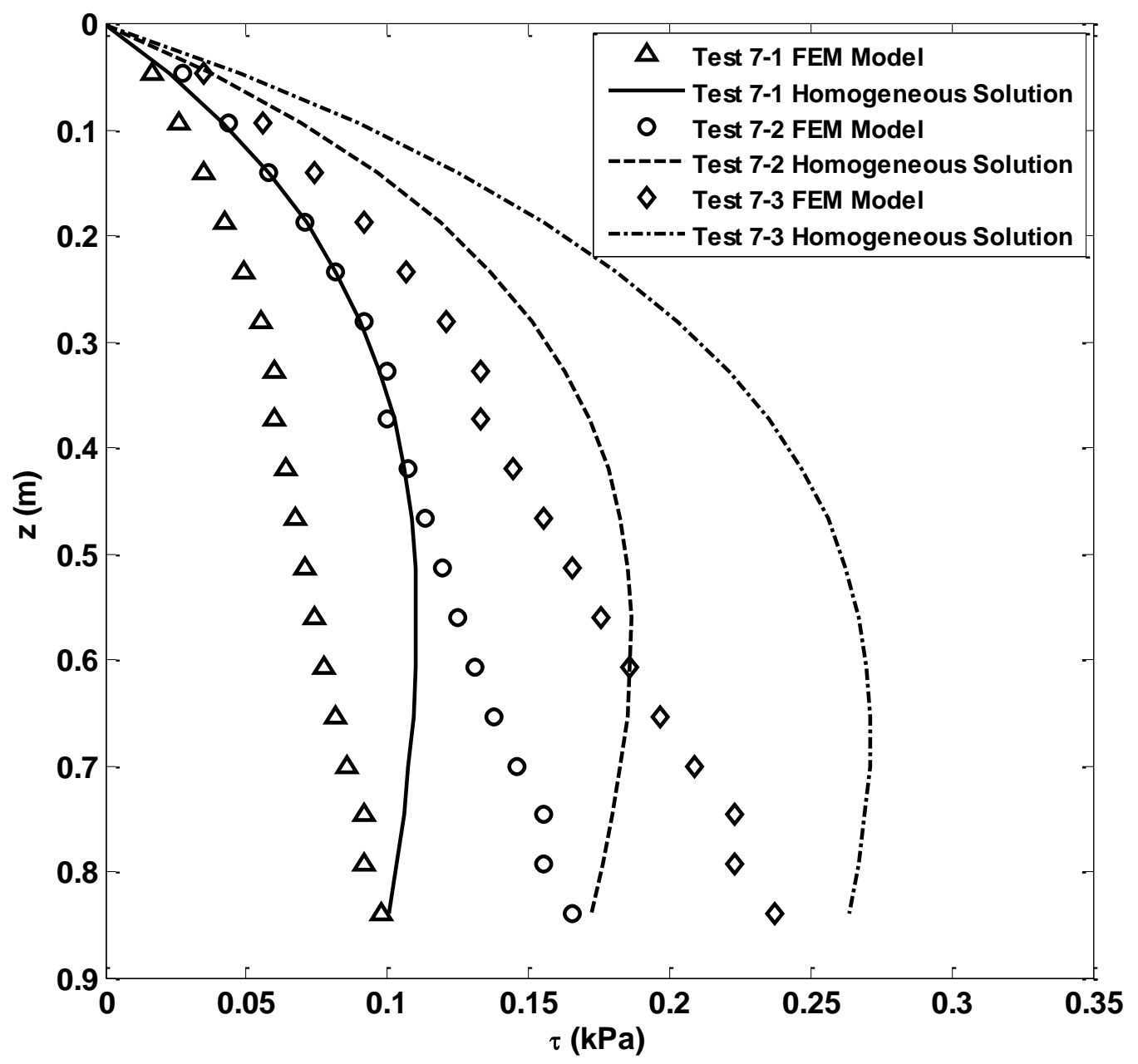

FIG. 15. Shear stress profiles for wave tank tests 7-1, 7-2, \& 7-3. 


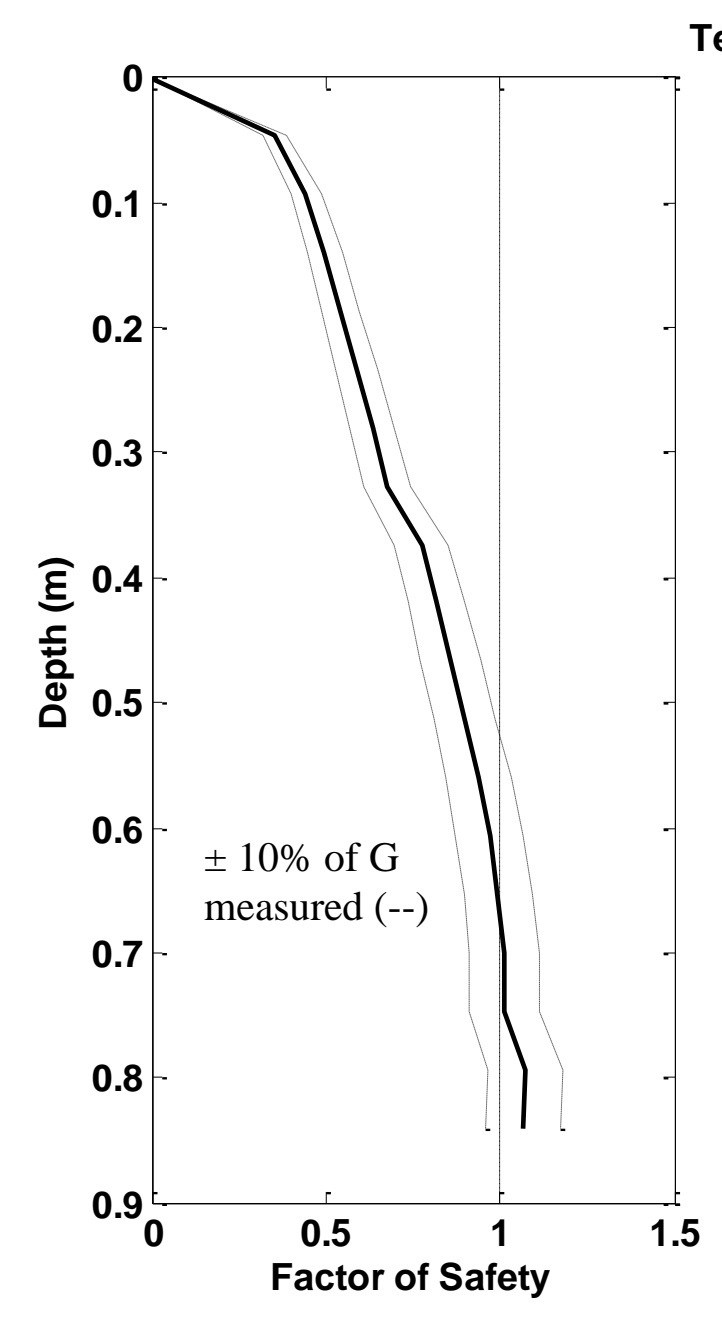

Test 7-1

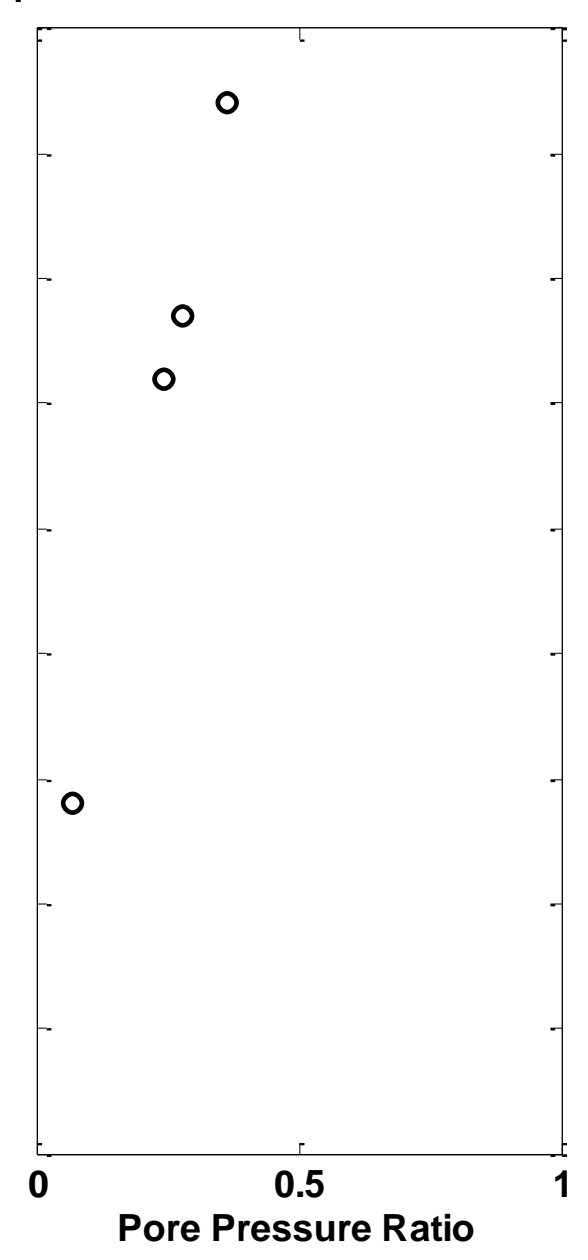

FIG. 16. Modeled factor of safety and measured pore pressure ratio (Clukey, Test 7-1). 

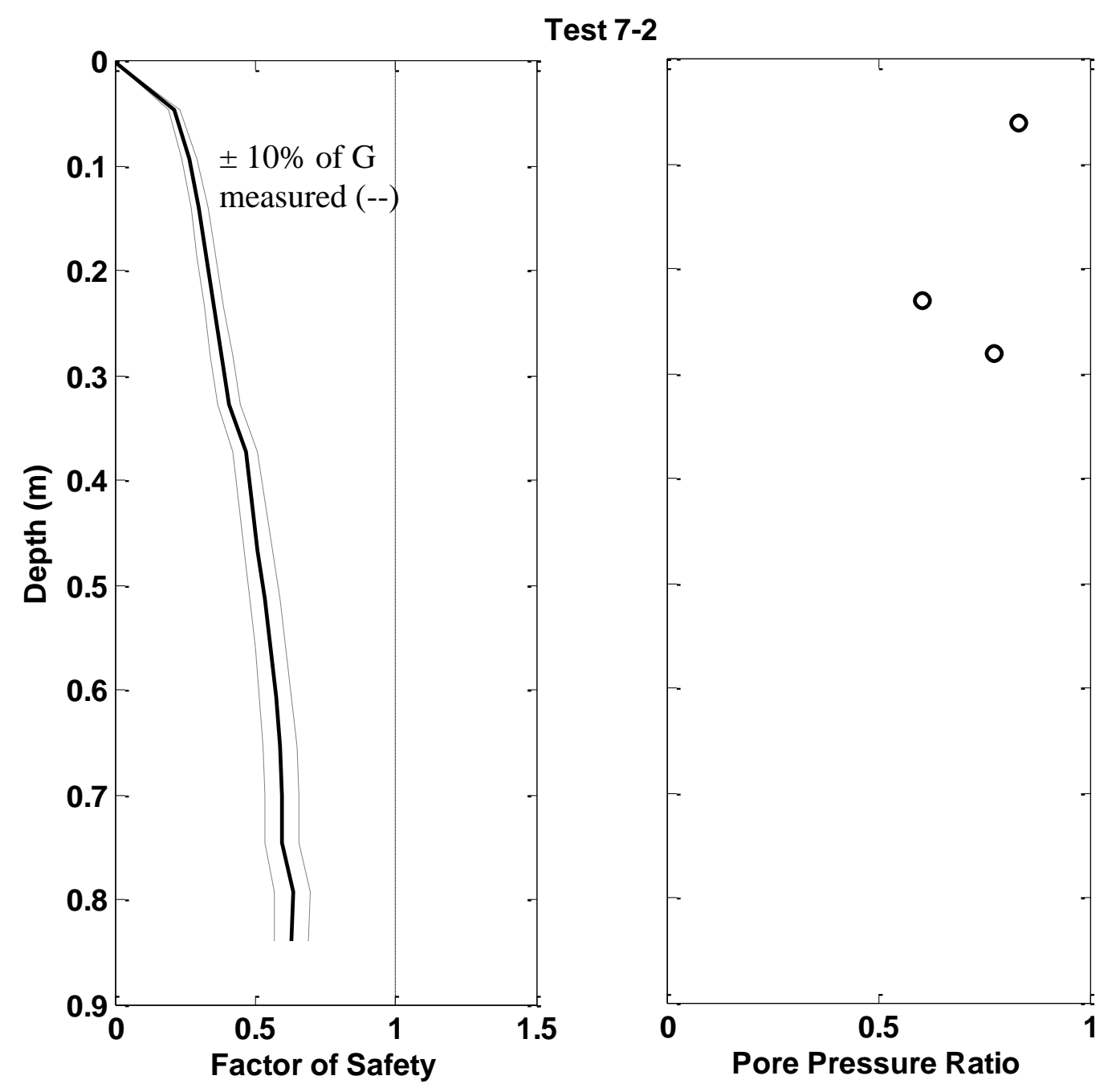

FIG. 17. Modeled factor of safety and measured pore pressure ratio (Clukey, Test 7-2). 


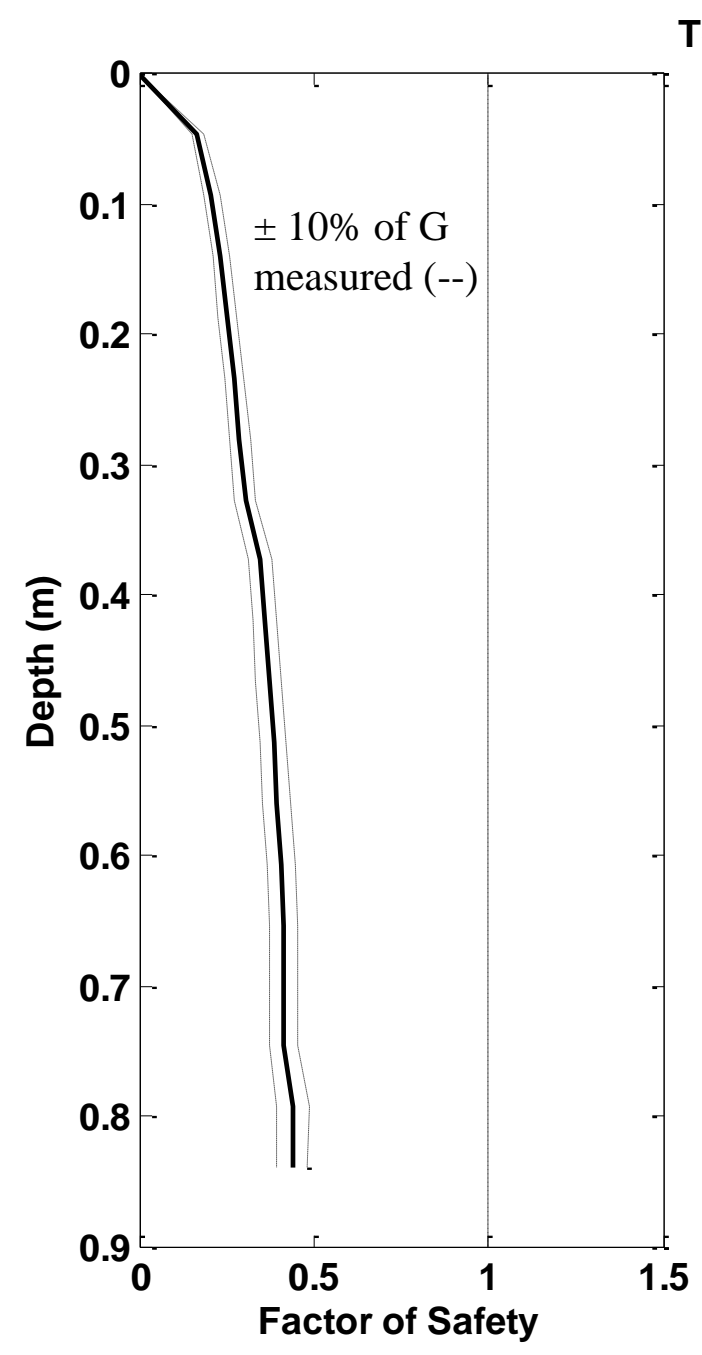

Test 7-3

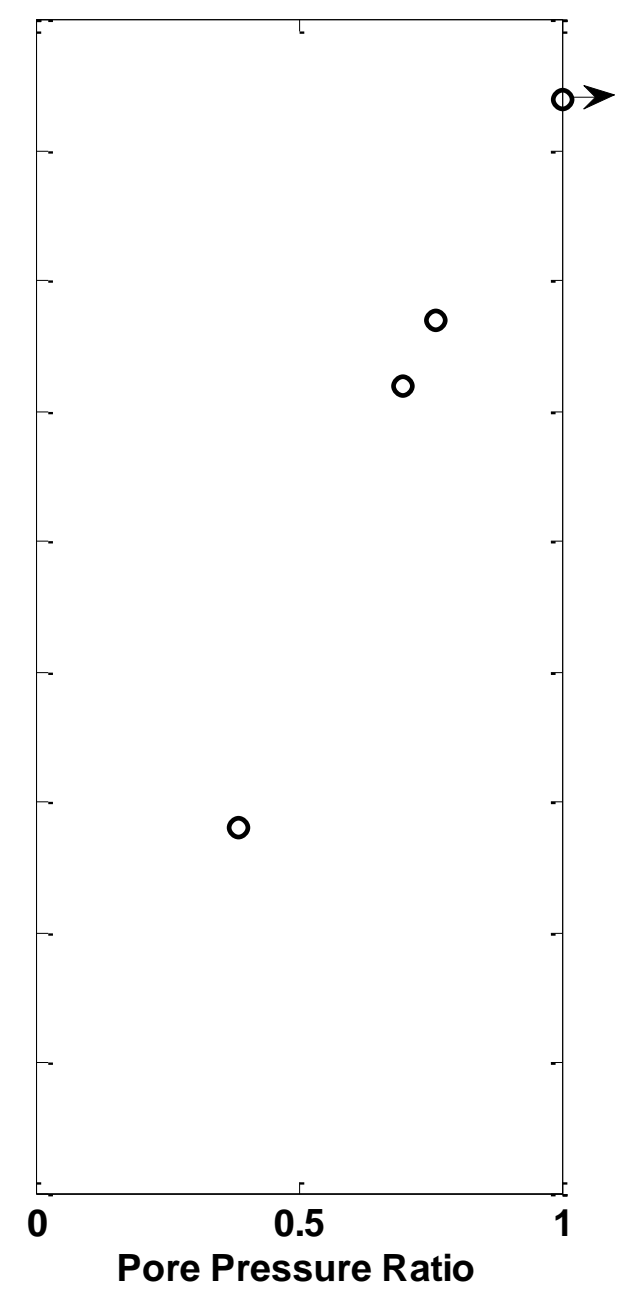

FIG. 18. Modeled factor of safety and measured pore pressure ratio (Clukey, Test 7-3). 


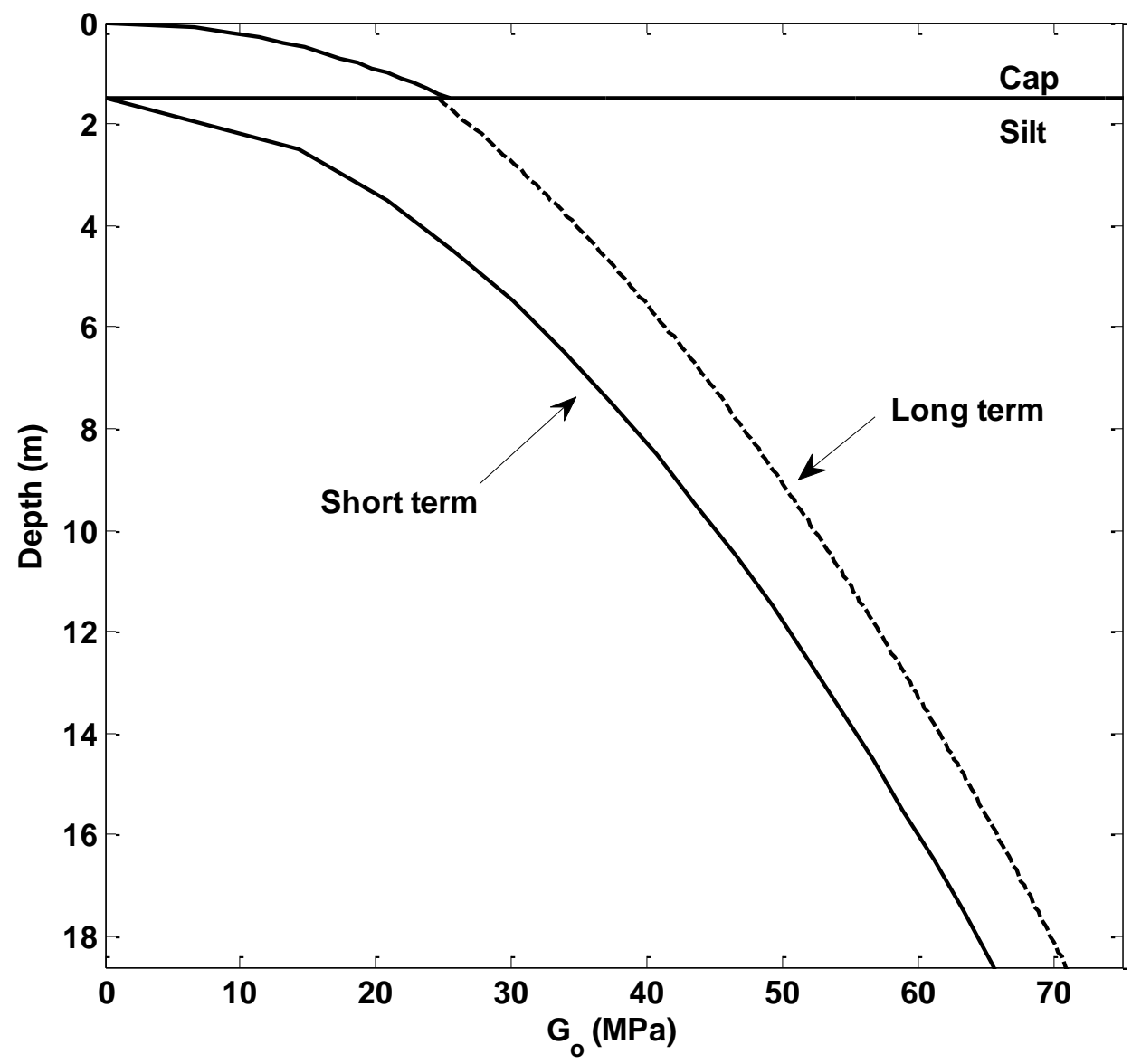

FIG. 19. Small strain shear modulus profiles for the cap and silt layers. 


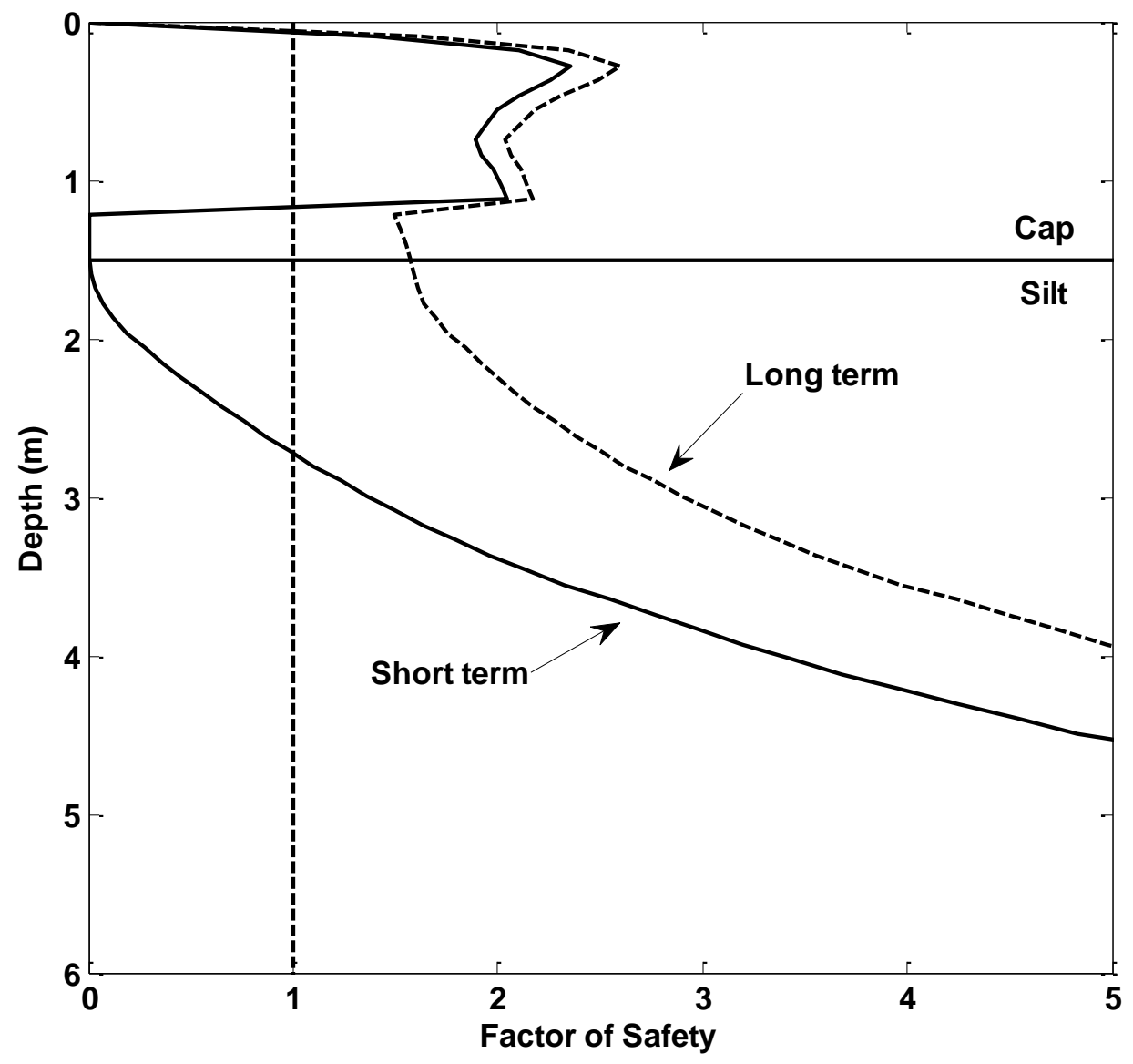

FIG. 20. Factor of safety against excess pore pressure in the short term and long term. 


\section{APPENDIX A. MATLAB CODE FOR CASE STUDY}

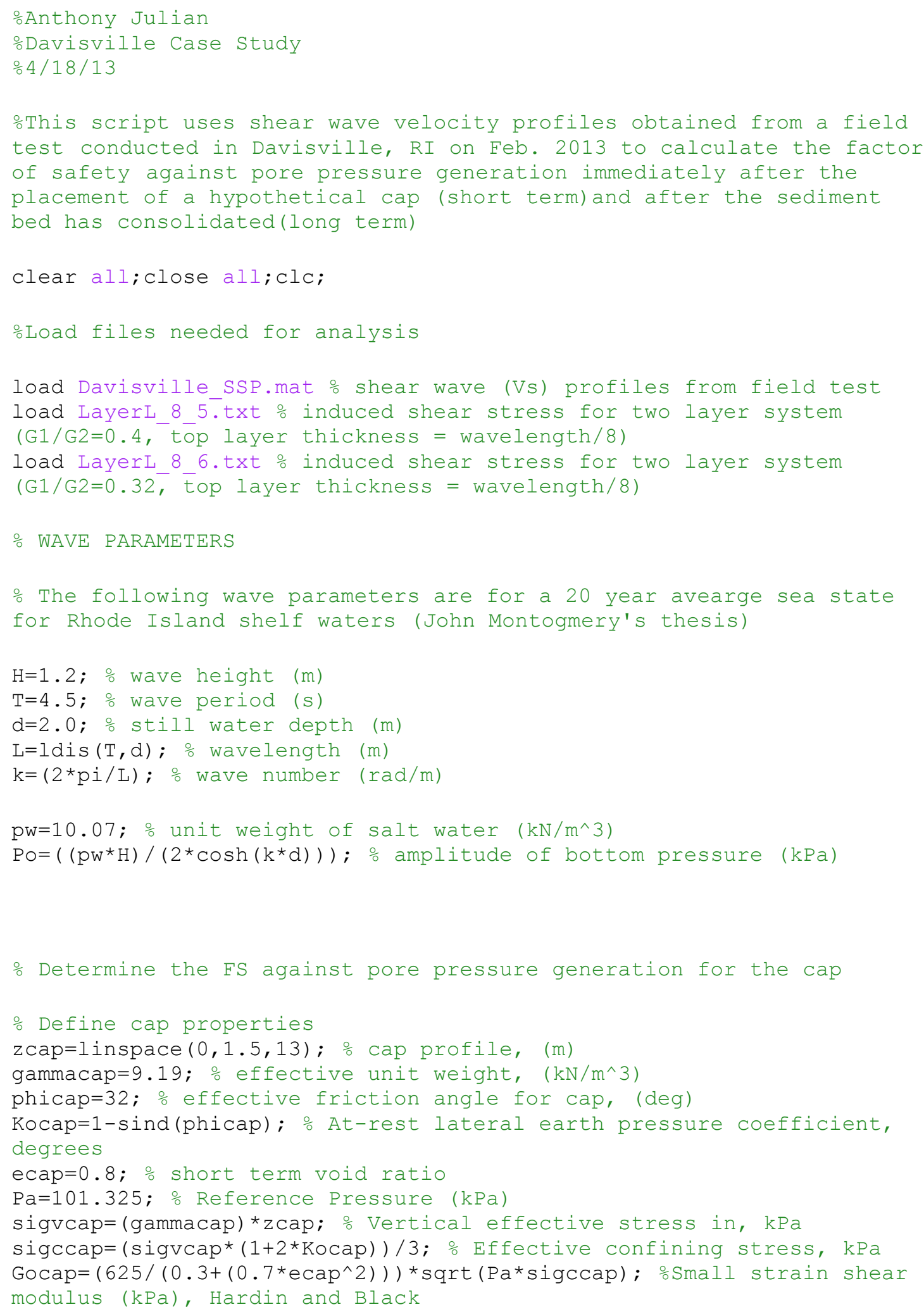


잉 Sect most representative shear stress profile for short and long term scenarios.

\% For convenience a linear elastic finite element analysis for each the short and long term conditions was conducted to produce accurate shear stress profiles.

\% The txt files LayerL_8_5.txt \& LayerL_8_6.txt are the results of the FE analysis for the short \& long term conditions respectively.

\% thcap MUST BE COMMENTED OR UNCOMMENTED TO CALCULATE THE SHORT

\% AND LONG TERM SCENARIOS SEPERATELY

thcap=Po*[LayerL_8_5 $(1: 13,3)]$ '; $\%$ short term shear stress profile, $(\mathrm{kPa})--(\mathrm{G} 1 / \mathrm{G} 2=0 . \overline{4})$

\%thcap $=$ Po* [LayerL_8_6 $(1: 13,3)]$ '; 응 long term shear stress profile, $(\mathrm{kPa})--(\mathrm{G} 1 / \mathrm{G} 2=0.3 \overline{2})$

\% Calculate Degradation Factor (DF - iterative approach)

$\operatorname{DFcap}=0.5 *$ ones $(1$, length (thcap) );

DFinitialcap=DFcap +1 ;

TOL $=.00001$;

$i=0$;

while ((abs (DFcap (2) -DFinitialcap (2))) >TOL)

DFinitialcap=DFcap;

$i=i+1$;

straincap=thcap. / (Gocap. *DFcap) ;

$\mathrm{K}=0.5 *\left(1+\tanh \left(\log \left((.000102 . / \operatorname{straincap}) \cdot{ }^{\wedge} 0.492\right)\right)\right) ;$

$\mathrm{m}=0.272 *\left(1-\tanh \left(\log \left((.000556 . / \operatorname{straincap}) .^{\wedge} 0.4\right)\right)\right)$;

$\mathrm{DFcap}=\mathrm{K} \cdot{ }^{*}(\mathrm{sigccap}) \cdot{ }^{\wedge} \mathrm{m}$;

end

o Cap profile's

Gcap $=\left(\right.$ Gocap. $\left.{ }^{\text {DFcap }}\right) ;$ \% Secant Shear Modulus, kPa

Straincap=thcap./Gcap; \% Cyclic shear strain in soil, kPa

threscap $=1.55 e-4 ;$ Threshold shear strain ( IP=0)

$\mathrm{FS}=($ threscap*ones $(1$, length $(\mathrm{zcap})))$. Straincap; ․․․ Factor of Safety in cap

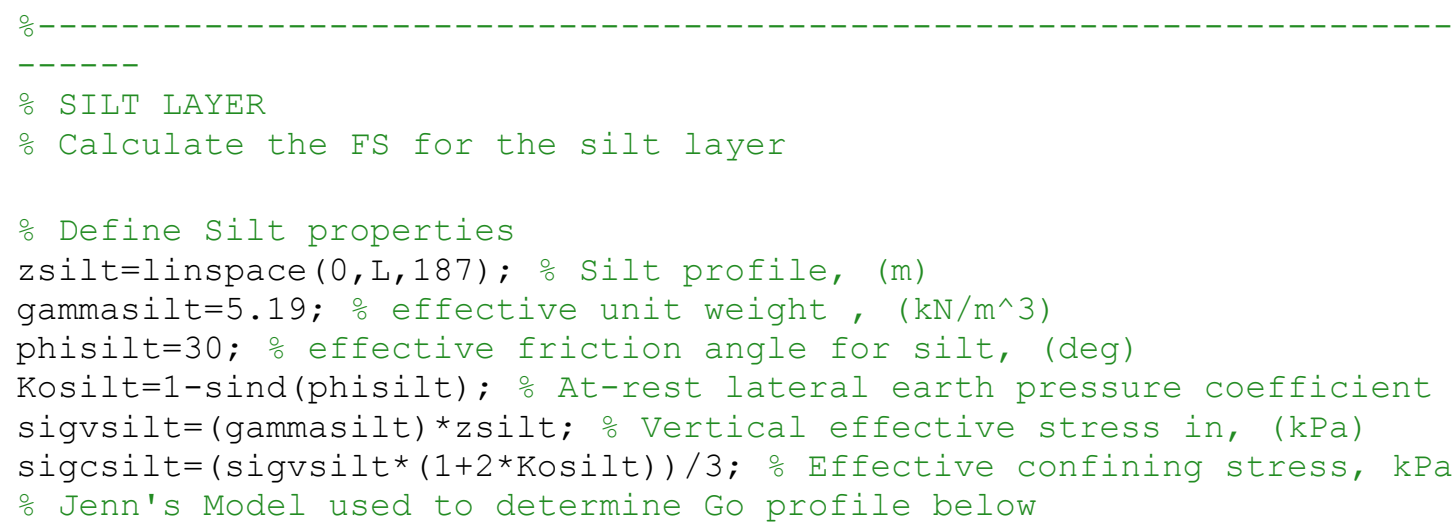




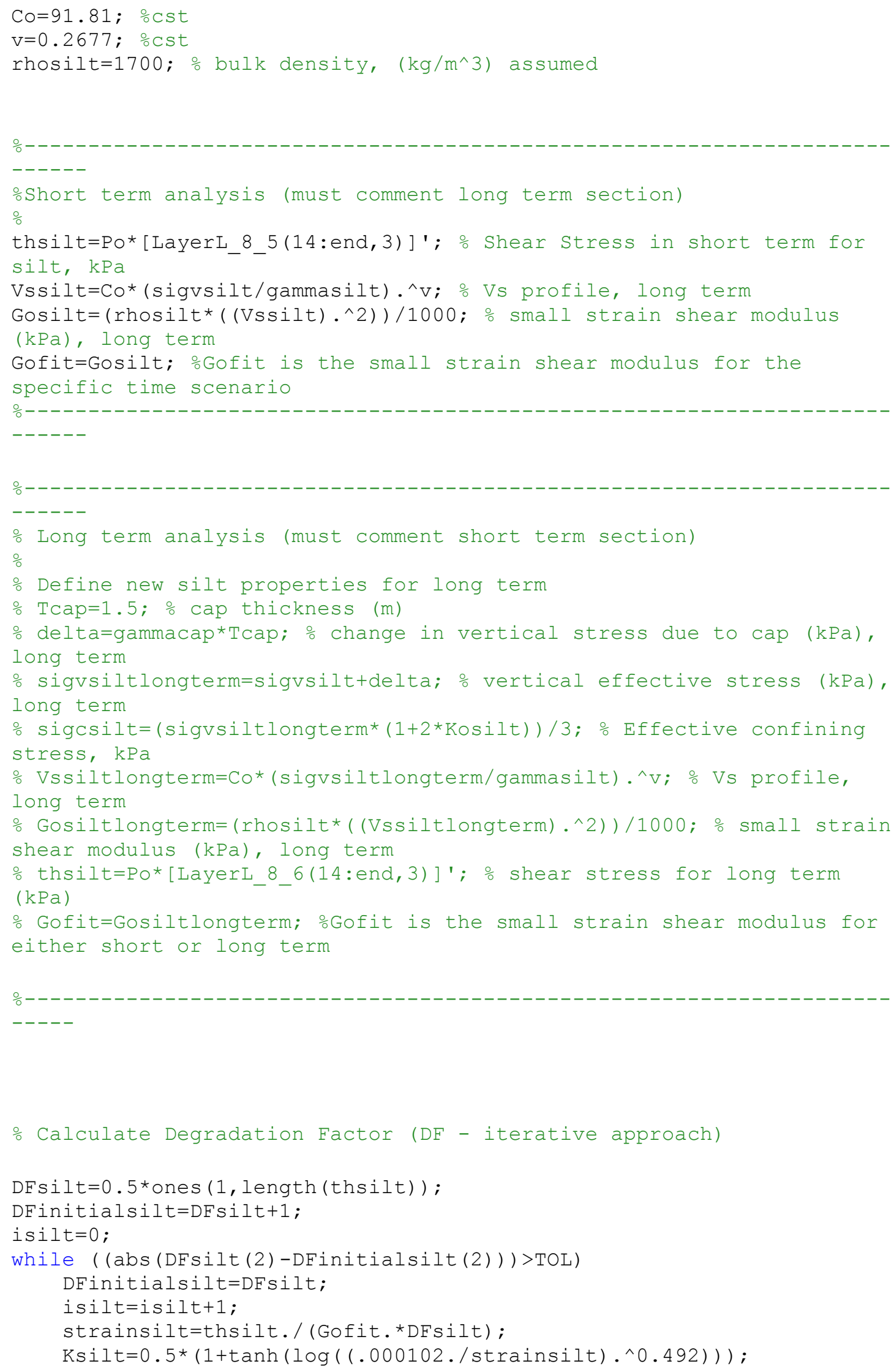




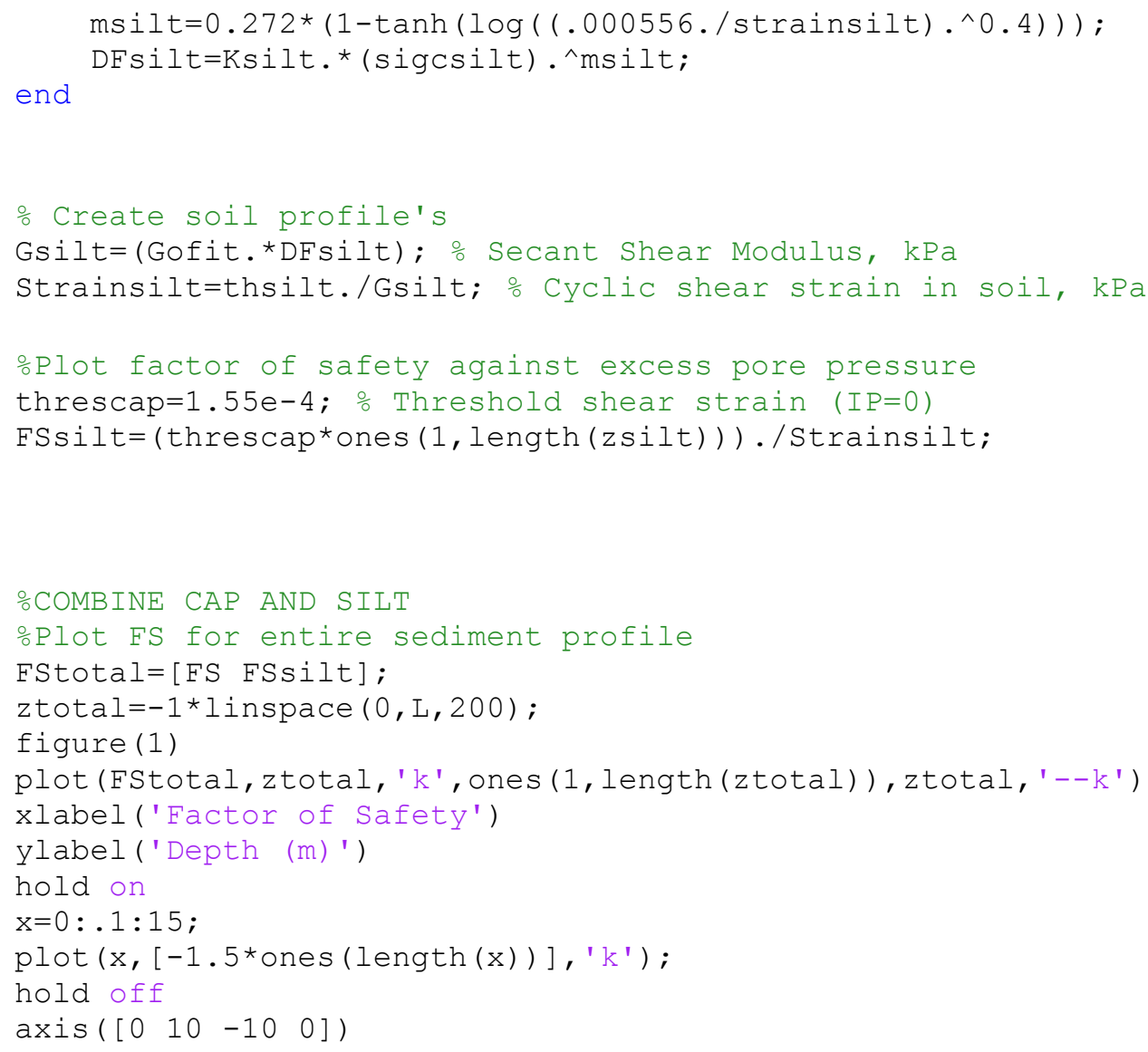

